MARTÍNEZ, Marco. "La graduación del deber de cuidado en el delito culposo por Actos de mala praxis médica: un análisis dogmático, jurisprudencial y económico".

Polit. crim. Vol. 6, № 12 (Diciembre 2011), Art. 1, pp. 214 - 251.

[http://www.politicacriminal.cl/Vol_06/n_12/Vol6N12A1.pdf]

\title{
La graduación del deber de cuidado en el delito culposo por actos de mala praxis médica: un análisis dogmático, jurisprudencial y económico
}

\author{
Marco Martínez Lazcano ${ }^{1}$ \\ Licenciado en Ciencias Jurídicas, Pontificia Universidad Católica de Valparaíso \\ Magíster en Derecho Penal, Universidad de Talca \\ marmartinez@utalca.cl
}

\section{Resumen}

La doctrina chilena mayoritaria ha estimado que el artículo 491 del Código Penal, que sanciona el delito culposo de homicidio y lesiones por negligencia médica, requiere, junto con la inobservancia de la lex artis médica, un mayor deber de cuidado que se traduce en un estándar de culpa leve para la configuración del tipo penal. Sin embargo, el autor postula que dicho baremo debe interpretarse correctamente como de culpa grave a fin de brindar una respuesta adecuada al fenómeno moderno conocido como "medicina defensiva", el cual resulta en una alteración de las estructuras de comportamiento colectivo de los sujetos partícipes del conflicto penal subyacente, conllevando una afectación refleja sobre el bien jurídico tutelado. Para fundar este planteamiento se recurre a elementos hermenéuticos vinculados a criterios de asignación eficiente de recursos sociales, y al análisis global del sistema jurídico a la luz de los principios cardinales de fragmentariedad y última ratio. Finalmente, se plantea inferir pautas jurisprudenciales a objeto de plasmar el concepto de culpa grave de contenido homogéneo, referenciable para un número indeterminado de casos.

\begin{abstract}
The majority of Chilean doctrine has stated that article 491 of the Penal Code, which sanctions medical malpractice, requires, together with breach of the medical lex artis, a greater duty of care that translates into a standard of mere negligence to satisfy the legal description. Nevertheless, the author proposes that this standard should be interpreted as gross negligence, in order to obtain an adequate response to modern phenomena known as "defensive medicine", which results in an alteration of collective behavioral structures of subjects participant to the underlying penal conflict. To base this proposal, the article resorts to hermeneutic elements linked to efficient allocation of social resources criteria, and a global analysis of the legal system in light of cardinal principles of fragmentation and last resort. Finally, the need to infer jurisprudential guidelines is presented, to nurture the

${ }^{1}$ El autor agradece a su amada esposa Eugenia Ramos Bernal y a Fernando Londoño Martínez, Nicole Selamé Glena, Andrés Benavides Schiller, Nicolás Oxman Vilches y Marco Zamora Uribe, por su apoyo, observaciones, críticas e ideas.
\end{abstract}


MARTÍNEZ, Marco. "La graduación del deber de cuidado en el delito culposo por Actos de mala praxis médica: un análisis dogmático, jurisprudencial y económico".

concept of gross negligence with homogeneous content, referential for an undetermined number of future cases.

\section{Palabras Clave}

Negligencia médica, mala praxis, delito culposo, lex artis, medicina defensiva, culpa grave, culpa leve, principio de fragmentariedad, principio de última ratio, sobre prevención sobre protección.

\section{Key Words}

Medical malpractice, manslaughter, lex artis, gross negligence, defensive medicine, principle of fragmentation, principle of last resort, overdeterrence - overenforcement.

\section{Introducción}

Tradicionalmente se ha afirmado por nuestra doctrina que el delito culposo de homicidio o lesiones causado por actos de negligencia médica, hecho punible tipificado en el artículo $491^{2}$ del Código Penal Chileno, exige para su configuración la infracción de un determinado estándar de diligencia en relación a la denominada lex artis ad hoc médica, correspondiente a lo que en sede civil se denomina "culpa leve". En este sentido se ha pronunciado de manera expresa Garrido Montt, ${ }^{3}$ quien sostiene que de los términos empleados por los artículos 490, 491 y $492^{4}$ de nuestro código punitivo, se puede inferir una cierta cadena de graduación. Así, la expresión "negligencia culpable" utilizada por el citado artículo 491 del Código Penal se traduciría en una exigencia de mayor cuidado respecto de la fórmula de sujeto activo universal del artículo $490,{ }^{5}$ fundado en que las

\footnotetext{
${ }^{2}$ Artículo 491 del Código Penal Chileno, inciso primero: "El médico, cirujano, farmacéutico, flebotomiano o matrona que causare mal a las personas por negligencia culpable en el desempeño de su profesión, incurrirá respectivamente en las penas del artículo anterior".

${ }^{3}$ GARRIDO MONTT, Mario, Derecho Penal: Parte General, Tomo II, Cuarta edición, Santiago: Editorial Jurídica de Chile, 2007, pp. 223-224.

${ }^{4}$ Artículo 492 del Código Penal Chileno, inciso primero: "Las penas del artículo 490 se impondrán también respectivamente al que, con infracción de reglamentos y por mera imprudencia o negligencia, ejecutare un hecho o incurriere en una omisión que, a mediar malicia, constituiría un crimen o simple delito contra las personas". Existe acuerdo en la doctrina para sostener que la expresión "mera imprudencia o negligencia" implica una exigencia de "culpa leve", fundamentalmente por cuanto la norma requiere que el autor infrinja los reglamentos pertinentes, ignorando la advertencia orientada a prevenir el hecho riesgoso. Ver: BUSTOS RAMÍREZ, Juan, El delito culposo, Santiago: Editorial Jurídica de Chile, 1995, p. 56; GARRIDO, Derecho Penal, cit. nota $n^{\circ} 3$, p. 224; POLITOFF LIFSCHITZ, Sergio; MATUS ACUÑA, Jean Pierre; RAMÍREZ GUZMÁN, María Cecilia, Lecciones de Derecho Penal Chileno: Parte General, Segunda edición, Santiago: Editorial Jurídica de Chile, 2003, pp. 291-292.

${ }^{5}$ Artículo 490 del Código Penal Chileno: "El que por imprudencia temeraria ejecutare un hecho que, si mediara malicia, constituiría un crimen o simple delito contra las personas, será penado: $1^{\circ}$ Con reclusión o relegación menores en sus grados mínimos a medios, cuando el hecho importare crimen. $2^{\circ}$ Con reclusión o relegación menores en sus grados mínimos o multa de once a veinte unidades tributarias mensuales, cuando importare simple delito". La doctrina esta conteste en que la expresión "imprudencia temeraria" se traduciría
} 
profesiones descritas en aquella norma son creadoras de riesgos que precisan de más "acuciosidad en quien las realiza". ${ }^{6}$ En igual línea, aunque con matices, se pronuncia Etcheberry, ${ }^{7}$ quien si bien acepta el grueso de la tesis de Garrido Montt, hace presente la imposibilidad de formular criterios objetivos de nivelación, destacando la necesidad de entregar la labor en concreto a la prudencia del juez. Finalmente, se adhiere a esta posición Enrique Cury, ${ }^{8}$ quien expresamente admite que el tipo del artículo 491 del Código Penal crea un deber más estricto de evitar resultados lesivos, en vistas de las profesiones conceptualmente más riesgosas que se contemplan en la disposición en comento. Tal es el convencimiento de estos autores sobre la irrefutabilidad de esta posición, que Cury, por ejemplo, ha señalado en relación al artículo 491 del Código Penal, que

“(...) en suma, significa que se les hace, lógicamente, una mayor exigencia de cuidado que al común de los ciudadanos, pues basta la simple negligencia para hacerlos ya penalmente responsables por el daño que puedan ocasionar a quienes era su obligación curar. Esto es natural y no exige muchas explicaciones".

En sentido contrario, aunque tan sólo de lege ferenda y por razones de política criminal, se pronuncian los profesores Politoff, Matus y Ramírez, quienes sin embargo parecen admitir como tesis de lege lata, la señalada por la doctrina mayoritaria anteriormente apuntada. ${ }^{10}$

En la práctica judicial, sin embargo, este tema ha quedado un tanto eclipsado por otras consideraciones que parece tener presente la jurisprudencia de nuestros Tribunales Superiores al momento de resolver los casos reales. Así, por ejemplo, es común que las Cortes Chilenas que conocen negligencias médicas en sede penal concentren sus esfuerzos en determinar la concurrencia de los requisitos generales del delito culposo, y como nota

en un estándar de "culpa grave". GARRIDO, Derecho Penal, cit. nota $n^{\circ} 3$, p. 224; POLITOFF /MATUS/RAMÍREZ, Lecciones, cit. nota n 4, p. 291.

${ }^{6}$ GARRIDO, Derecho Penal, cit. nota no 3, p. 224.

7 ETCHEBERry ORTHUSTEGUI, Alfredo, Derecho Penal: Parte General, Tomo I, Tercera edición, Santiago: Editorial Jurídica de Chile, 1997, p. 322. Sin embargo, en ETCHEBERRY ORTHUSTEGUI, Alfredo, "Tipos Penales Aplicables a la Actividad Médica", Revista Chilena de Derecho, Vol. 13, (1986), pp. 271-280, p. 278, agrega un matiz, al estimar que el artículo 491 exigiría menos que la "imprudencia temeraria" del artículo 490 del Código Penal, pero "algo más" que la "mera imprudencia" requerida por el artículo 492, norma - esta última - que para fundamentar semejante grado de exigencia, previene adicionalmente la infracción de reglamentos.

${ }^{8}$ CURY URZUA, Enrique, Derecho Penal: Parte General, Octava edición, Santiago: Ediciones Universidad Católica de Chile, 2005, p. 345.

9 CURY URZUA, Enrique, "Contribución al estudio de la responsabilidad médica", Revista de Ciencias Penales, tomo XXXVII, (1981), pp. 97-105, p. 105.

${ }^{10}$ POLITOFF /MATUS/RAMÍREZ, Lecciones, cit. nota $n^{\circ} 4$, p. 292, nota al pie n ${ }^{\circ} 351$. También: BUSTOS, El delito, cit. nota ${ }^{\circ}$ 4, p. 56; LABATUT GLENA, Gustavo; ZENTENO VARGAS, Julio, Derecho Penal, Parte General, Tomo II, Séptima Edición, Santiago: Editorial Jurídica de Chile, 1990, pp. 248-249. Por su parte NOVOA MONREAL, Eduardo, Curso de Derecho Penal: Parte General, Santiago: Editorial Jurídica de Chile, 2005, pp. 509-510, señala que si bien la aplicación de las escalas diferenciadas de culpa del art. 44 del Código Civil al código punitivo nacional debe considerarse hoy una postura definitivamente abandonada, igualmente advierte una graduación en las expresiones contenidas en los artículos 490, 491 y 492 del Código Penal, en el tipo subjetivo. 
MARTÍNEZ, Marco. "La graduación del deber de cuidado en el delito culposo por Actos de mala praxis médica: un análisis dogmático, jurisprudencial y económico".

particular referida a la mala praxis médica, se intenta dilucidar si existió o no una inobservancia de la denominada lex artis ad hoc del galeno. Esta última cuestión parece destacar como el gran tema de la responsabilidad médica penal en nuestra jurisprudencia criolla. A modo de ejemplo, la Excma. Corte Suprema ha señalado en un fallo de 15 de septiembre de $2008,{ }^{11}$ que:

"Actúa culposamente el que infringe un deber de cuidado que personalmente le incumbe y puede prever la aparición del resultado, el que o bien no prevé o bien, previéndolo, confía imprudentemente en poder evitarlo. En definitiva, para que nazca la responsabilidad culposa, será necesario: a) que exista un comportamiento voluntario; b) que la acción u omisión origine un resultado antijurídico; c) que el resultado sea previsible; d) que exista la obligación de preverlo; y e) que haya relación causal entre la acción u omisión y el resultado típico. La Teoría de la Culpa está cimentada, entonces, en dos pilares básicos: 1 . el deber de cuidado, que obliga al sujeto a poner en su actividad una atención suma a objeto de no dañar los bienes protegidos por el legislador, y 2. la previsibilidad del resultado, establecido a partir de parámetros ordinarios o comunes, puesto que nadie puede responder por resultados imprevisibles. Existirá culpa por el solo hecho de que el sujeto activo haya ejecutado el acto prohibido o no haya realizado el ordenado por la ley o el reglamento, pues significa que omitió las medidas de prudencia o precaución necesarias para evitar un daño, reduciéndose la labor del tribunal a averiguar, conforme al mérito de los antecedentes, si medió conducta culposa por parte del encausado y quebrantamiento de reglamentos" 12

No se ha asentado, por tanto, una distinción jurisprudencial expresa a nivel de Tribunales Superiores ${ }^{13}$ referida a qué grado o intensidad de negligencia debe concurrir, en relación a la infracción de la lex artis médica, para que se verifique el tipo penal previsto en el artículo 491 del Código Penal. Por el contrario, generalmente se estima que la reunión de los requisitos comunes del delito culposo configura el ilícito, conformándose los tribunales con una vaga referencia al concepto de "conducta negligente o imprudente". Lo anterior se opone por cierto a lo previsto en otras legislaciones nacionales, en que la jurisprudencia se ha encargado de fijar criterios para distinguir entre imprudencias graves y leves ${ }^{14}$ aunque ello por cierto se debe, más que a una divina iluminación de los magistrados, a una imposición de la legislación positiva de los estados, que expresamente establecen consecuencias jurídicas distintas en uno y otro caso.

En el presente trabajo intentaremos demostrar, en contra de la tesis dominante chilena, que una correcta interpretación - ahora de lege lata - del artículo 491 del Código Penal, implica entender que dicha norma exige un estándar de cuidado de "culpa grave" para su configuración, y no de "culpa leve", siguiendo la terminología que la doctrina ha tomado

\footnotetext{
${ }^{11}$ Indicador Legal Publishing $\mathrm{n}^{\circ} 39754$.

${ }^{12}$ Estos considerandos se repiten de manera literal en otros fallos de la Corte Suprema, por ejemplo: en fallo de la Corte Suprema de fecha 4 de mayo de 2008, indicador Legal Publishing n ${ }^{\circ} 39232$.

${ }^{13}$ Sin embargo podemos encontrar criterios de diferenciación de "culpa grave" en algunas sentencias de nuestra judicatura nacional, según veremos más adelante.

${ }^{14}$ En España y Estados Unidos expresamente, lo cual analizaremos más adelante en detalle.
} 
del Derecho civil en esta materia. Para ello, pasaremos a desarrollar tres grupos de argumentos: de política criminal, de principios fundamentales de un Derecho penal de corte liberal, y de dogmática jurídica.

\section{El problema del deber de cuidado médico y el fenómeno de la medicina defensiva}

El aumento explosivo de denuncias en materia de responsabilidad penal médica constituye, sin duda, un fenómeno propio de nuestros tiempos. En efecto, en nuestro país sólo en el año 2005 el Servicio Médico Legal recibió un total de 309 casos nuevos por negligencia médica, de los cuales 239 pertenecen a la salud pública, mientras que 70 a la salud privada. De los informes evacuados por los peritos médicos legales se ha concluido que en un $12,63 \%$ de los casos el diagnóstico o tratamiento se apartó de la normas de la especialidad (lex artis), un 1,71\% de los mismos incurrió en responsabilidad institucional, mientras que en un 2,05\% existió responsabilidad institucional y del equipo de salud. En contraste, se estimó que un 78,50\% no infringió la lex artis médica, mientas que en un 5,12\% no se pudo tener un informe pericial concluyente. ${ }^{15}$ Lo anterior se confirma con las cifras proporcionadas por el Instituto Médico Legal, las que registran un incremento en un 415\% en el número de casos ingresados a pericia médica por demandas de mala praxis en el periodo comprendido entre los años 1991 y 2001, lo cual fue ratificado por estadísticas de FALMED del año 2001, revelándose, sin embargo, que en un $85 \%$ de los casos los resultados fueron favorables para los médicos. ${ }^{16}$

En otros países, el fenómeno es de similares características. En el Reino Unido un estudio ${ }^{17}$ concluyó que si bien la tasa de condena durante las últimas dos décadas era del orden del $30 \%$, el número de médicos acusados por homicidio culposo había sufrido un incremento dramático. Así, se señala que la Fiscalía de la Corona acusa a demasiados médicos, incluso conforme a sus propias pautas y metas de gestión. ${ }^{18}$

Por su parte, en España la situación es análoga y se apuntan por la doctrina sus posibles causas. Por un lado, se señala que el aumento sostenido de las denuncias en materia penal se debe a una mayor sensibilización social frente a los "errores médicos", llegándose incluso al extremo de que los usuarios del sistema propugnan la publicación de listas con los nombres de los galenos condenados por imprudencia médica. Por otro lado, se señala que el desarrollo tecnológico y de eficacia de la medicina moderna, conlleva un mayor riesgo, y por tanto, una mayor probabilidad para el paciente de resultar lesionado. Lo anterior se suma al hecho de que el simple aumento del número de médicos, posibilita - por simple cuestión de estadística - un alza en los casos de negligencia. Finalmente, se

\footnotetext{
${ }^{15}$ En: http://www.sml.cl

${ }^{16}$ RITZ P., Juan; GARCÍA M., César; ORTEGA T., Dulia, "La reforma procesal penal chilena: nuevo marco médico-legal del ejercicio de la radiología", Revista Chilena de Radiología, Vol. 11, n 3, (2005), pp. 142149 , p. 144.

17 E. MACDOWELL, Sarah, "Doctors charged with manslaughter in the course of medical practice, 1795 2005: a literature review", Journal of the Royal Society of Medicine, Vol. 99, (2006), pp. 309 - 314, p. 309.

${ }^{18}$ E. MACDOWELL, "Doctors", cit. nota no 17, p. 314.
} 
MARTÍNEZ, Marco. "La graduación del deber de cuidado en el delito culposo por Actos de mala praxis médica: un análisis dogmático, jurisprudencial y económico".

argumenta que el desarrollo social y cultural de los pueblos trae aparejado una mayor conciencia de los derechos del usuario del sistema, junto con el surgimiento de nuevos mecanismos jurídicos para obtener la reparación de los perjuicios producidos por una eventual negligencia sanitaria. ${ }^{19}$ La vía penal resulta ser entonces la más recurrida, con preferencia a la civil, especialmente por la celeridad de su procedimiento, a lo cual en Chile podríamos agregar como ventaja su mayor libertad en materia de prueba. ${ }^{20}$

Ahora bien, el problema que conlleva este escenario es el nacimiento de una sensación de inseguridad en el profesional médico que se traduce en el desarrollo fáctico de la llamada "medicina defensiva", 21 concepto que conforme la definición elaborada por la Congressional Office of Technology Assessment (OTA), ocurre cuando "los médicos ordenan exámenes, procedimientos o visitas, o evitan pacientes o procedimientos de alto riesgo, principalmente (pero no necesariamente de manera exclusiva) para reducir su exposición a la responsabilidad por mala praxis médica". ${ }^{22}$ Ello implica distinguir entre dos tipos de medicina defensiva. La primera especie, denominada "positiva", se caracteriza por la realización de una amplia gama de procedimientos, mayores exámenes diagnósticos y visitas, más recetas farmacológicas, estadías hospitalarias excesivas, etc. La medicina defensiva "negativa", por su parte, se manifiesta en el galeno que restringe su ejercicio profesional a aquellos pacientes de bajo riesgo, evitando casos complejos o de urgencia. ${ }^{23}$

Como señala Revuelta Iglesias, ${ }^{24}$ ello significa que el médico no apuntará sus esfuerzos tan sólo a la sanación del enfermo, sino que ante todo le concernirá actuar del modo más idóneo para anticipar cualquier posible reclamo de los usuarios, lo cual coloca un peso adicional sobre la prestación profesional, con los efectos que ello trasunta sobre ésta. Se señala también que dicho fenómeno acarrea una alteración en la lex artis médica, entendido como baremo de normalidad en la atención, mutando artificialmente en un criterio de mayor exigencia con el único objeto de evitar futuras denuncias, parámetro que sólo debiese variar conforme al avance científico, pero no por los incentivos que resultan del desarrollo preventivo de una "medicina defensiva".

En Chile, Jaime Pérez Olea ${ }^{25}$ ha señalado que la extrema judicialización de la medicina puede producir un cambio en la relación médico-paciente, trastocándola como calculadora por parte del médico y aprensiva por parte del paciente. Asimismo, es común afirmar que los galenos tendrán la tendencia a abstenerse de actuar ante emergencias graves; que las

\footnotetext{
${ }^{19}$ HAVA GARCÍA, Esther, La imprudencia médica, Valencia: Tirant Lo Blanch, 2001, pp. 11-13.

${ }^{20}$ Que se rige en nuestro sistema procesal por las reglas de la sana crítica y no de manera tasada.

${ }^{21}$ HAVA, La imprudencia, cit. nota n ${ }^{\circ}$ 19, p. 14.

22 SCLAR, David; HOUSMAN, Michael, "Medical malpractice and physician liability: examining alternatives to defensive medicine", Harvard Health Policy Review, Vol. 4, nº 1, (2003), pp. 75-84, p. 76.

${ }^{23}$ SCLAR/HOUSMAN, "Medical", cit. nota no 22, p. 76.

${ }^{24}$ REVUELTA IGLESIAS, Ana Victoria, "El riesgo de la Judicialización de la medicina", Educ. méd., Vol. $\mathrm{n}^{\mathrm{o}} 9, \mathrm{n}^{\mathrm{o}} 1$, (2006), pp. 55-64, p. 57. En: http://scielo.isciii.es/scielo.php?script=sci_arttext\&pid=S157518132006000600015\&lng=es\&nrm=iso, [visitado el 3-06-2011].

${ }^{25}$ PÉREZ OLEA, Jaime, "El tratamiento médico y la práctica médica", Revista de Ciencias Penales, tomo XXXVII, (1981), pp. 87-95, p. 89.
} 
especialidades que involucran un riesgo mayor quedan desiertas o insuficientemente cubiertas; que se obliga a los médicos a contratar costosos seguros con una consecuente alza en sus honorarios; y que se acarrea un aumento precoz de las especializaciones, lo cual es inconveniente en un país donde hay pocos médicos generales. Como causas, los operadores del sistema de salud en nuestro país ${ }^{26}$ señalan, junto a las indicadas anteriormente, que el avance en el desarrollo tecnológico en la medicina, la irrupción de la bioética y la modernización de la gestión en la atención médica (con la consecuente marginación de los profesionales de la salud en la dirección y administración sanitaria ${ }^{27}$ ), erosiona la relación médico-paciente al volverse horizontal, creando en el paciente la sensación de que los resultados negativos en los tratamientos y diagnósticos terapéuticos se deben exclusivamente a fallas de los profesionales médicos, a quienes se ha de exigir respuestas y reparaciones, sin advertir que tales consecuencias pueden deberse a condiciones previas del usuario, o la concreción de ciertos riesgos propios y naturales de cualquier intervención médica.

Un estudio empírico realizado por David Sclar y Michael Housman en el año 2003, ${ }^{28}$ demostró que más allá del impacto financiero - directo (resarcimiento) e indirecto (aumento de las primas de seguros) - que trae aparejada una sanción judicial por negligencia, son las consecuencias públicas y personales de la judicialización lo que más influye en el comportamiento "defensivo" del médico. Así, cuando un profesional de la salud es acusado de mala praxis, sus habilidades son colocadas públicamente en tela de juicio, su reputación destruida, pudiendo resultar en una pérdida de sus clientes o incluso de sus empleos. Los profesionales entrevistados por estos autores describieron la demanda por negligencia como "una de las épocas más complicadas en la vida de un doctor, especialmente ese día cuando te demandan por primera vez", ${ }^{29}$ sintiéndose insultados y humillados por la exposición pública de sus errores. Junto con ello, la mayoría de los facultativos presenta una desconfianza y hostilidad hacía el sistema legal, los abogados y las decisiones de los tribunales, que consideran muchas veces como arbitrarias. ${ }^{30}$

Asimismo, en tanto el delito penal implica por definición un hecho ilícito, que puede eventualmente configurar uno de los elementos de la responsabilidad civil aquiliana o extracontractual, ${ }^{31}$ (acción civil que puede ejercerse conjuntamente con la penal dentro del

\footnotetext{
${ }^{26}$ RITZ/GARCÍA/ORTEGA, "La reforma", cit. nota ${ }^{\circ}$ 16, p. 143.

27 Según lo señalan RITZ/GARCÍA/ORTEGA, "La reforma", cit. nota $\mathrm{n}^{\circ}$ 16, p. 143, la progresiva desaparición del ejercicio privado médico y su reemplazo por grandes corporaciones que toman el control de la gestión médica con criterios de mercado, imponen una carga de trabajo adicional que en muchas ocasiones crea conflictos entre la labor profesional y la calidad de la atención prestada.

${ }^{28}$ SCLAR/HOUSMAN, "Medical", cit. nota $\mathrm{n}^{\circ} 22$, p. 77.

${ }^{29}$ SCLAR/HOUSMAN, "Medical”, cit. nota n ${ }^{\circ} 22$, p. 77. La traducción es nuestra.

${ }^{30}$ SCLAR/HOUSMAN, "Medical", cit. nota $\mathrm{n}^{\circ} 22$, p. 77. Los autores relatan una entrevista a un médico que sospecha haber sido demandado únicamente porque tenía una cobertura de tres millones de dólares en seguro.

${ }^{31} \mathrm{Si}$ bien cabe tener presente que tales planos de responsabilidad no necesariamente coincidirán en todos los casos, principalmente por cuanto el delito penal se configura primeramente en base al principio de tipicidad, mientras que los ilícitos civiles atienden al daño como elemento definidor. Esta bifurcación se produce especialmente con nuestra interpretación del artículo 491 del Código Penal, en tanto en base a ella podemos
} 
MARTÍNEZ, Marco. "La graduación del deber de cuidado en el delito culposo por Actos de mala praxis médica: un análisis dogmático, jurisprudencial y económico”.

proceso acusatorio), las eventuales reparaciones civiles que puede potencialmente originar el abuso de denuncias o querellas por mala praxis médica, trae consigo todas las consecuencias que son propias de este ámbito privado, a nivel macro. Así, por ejemplo, en Estados Unidos (país en que más desarrollo ha tenido la litigación por medical malpractice) se ha señalado que la actual legislación en materia de responsabilidad médica civil (torts law) ha acarreado un costo socio-económico enorme, ${ }^{32}$ revelándose como ineficiente. Quienes postulan una reforma al sistema, ${ }^{33}$ señalan que dicha ineficiencia se debe a que el incremento en las demandas y querellas por malpractice, y las grandes sumas de dinero que declaran los tribunales en favor de los usuarios, crea un aumento en las primas de seguros médicos, que se traducen inevitablemente en un alza en el valor de los tratamientos. Lo anterior trae aparejado que los médicos evitan aquellas especializaciones de mayor incidencia de demandas, suspenden ciertos servicios médicos, se produce la migración de prestadores de salud hacia otros estados con sistemas de responsabilidad más laxos, y se genera el ya citado problema de la llamada medicina defensiva.

Ahora bien, los detractores de una eventual reforma al sistema argumentan que los costes, si es que existen, se justifican en tanto el daño originado por un error médico constituye una vulneración de sus derechos de bienestar social y sus prerrogativas como pacientes. ${ }^{34}$ Asimismo, se ha cuestionado la relación de causalidad entre el aumento de demandas por negligencia médica y los costes del sistema. ${ }^{35}$ En este sentido, se afirma que en términos de rentabilidad colectiva, los costes por juicios de negligencia médica son inferiores a los beneficios por concepto de mejoras en los servicios de salud que proporciona el sistema. ${ }^{36}$

Sin embargo, a pesar de estos cuestionamientos, la legislación norteamericana ha respondido con variadas reformas legales, atomizando la responsabilidad por mala praxis médica: limitando los montos de resarcimiento únicamente a daños no patrimoniales por

encontrar hechos que si bien dan origen a responsabilidad civil en sede extracontractual, no pueden sancionarse penalmente, en atención a que no cumplirían con el baremo de imputación penal requerido para aplicar el tipo del artículo 491 del Código Penal.

${ }^{32}$ Se señala que el costo de litigación por juicios de mala praxis médica ha aumentado en un $12 \%$ anual desde el año 1975. TOWERS PERRIN, Tillinghast, "U.S. Tort Costs and Cross-Border Perspectives: 2005 Update", Towers Perrin New York, (2005), pp. 1-23, p.4, En: http://www.towersperrin.com/tp/getwebcachedoc?webc=TILL/USA/2006/200603/2005 Tort.pdf\#searc\%20h $=\% 22$ Tillinghast $\% 20$ Towers $\% 20$ Perrin $\% 2$ C $\% 20$ U.S. $\% 20$ Tort $\% 20$ Cos $\% 0$ Ats $\% 20$ and $\% 20$ CrossBorder $\% 20$ Pe rspectives $\% 3 \mathrm{~A} \% 202005 \% 20 \mathrm{Upda} \% 0 \mathrm{Ate} \% 22$ [visitado el 3-06-2011].

${ }^{33}$ SHER, Noa, "New differences between negligence and strict liability and their implications in medical malpractice reform", University of Southern California Interdisciplinary Law Journal, Vol. 16, (2007), pp. 264, p. 4. En: http://www.ssrn.com/abstract=964728 [visitado el 3-06-2011].

${ }^{34}$ SHER, "New differences", cit. nota $\mathrm{n}^{\mathrm{o}} 33, \mathrm{p} .5$.

35 BAKER, Tom, The Medical Malpractice Myth, University of Chicago Press, 2005. p. 3, ha señalado que: "First, we know from the California study, as confirmed by more recent, better publicized studies, that the real problem is too much medical malpractice, not too much litigation".

${ }^{36}$ SHER, "New differences", cit. nota $n^{\circ}$ 33, p. 5. Ver también: MELLO, Michelle M.; STUDDERT, David M.; BRENNAN, Troyen A., "The New Medical Malpractice Crisis", New England Journal of Medicine, Vol. 348, (junio 2003), pp. 2281-2284; STEIN, Alex, "Fixing Medical Torts by Repositioning Inalienability and Contract", Cardozo Legal Studies Research Paper, $\mathrm{n}^{\mathrm{o}}$ 151, 2006, pp. 1 y ss. En: http.//www.ssrn.com/abstract=889474 [visitado el 3-06-2011]. 
dolor y sufrimiento (damage caps $^{37}$ ), estableciendo límites a los gastos legales, y fijando plazos de prescripción más breves (statue of limitations). Durante el periodo 2003-2006 el gobierno de G.W. Bush intentó imponer legislación federal en materia de responsabilidad médica. El proyecto proponía fijar un tope de 250.000 dólares de indemnización, límites en honorarios legales, estableciendo un plazo de prescripción de 3 años para accionar a contar del hecho imprudente o 1 año desde su descubrimiento, y restringiendo severamente las reparaciones punitivas. $^{38}$

A las reacciones del sistema norteamericano pueden agregarse las de otros países, en los cuales se ha restringido la procedencia de acciones legales por mala praxis médica, condicionándose su tramitación a la existencia previa de una opinión de otro profesional médico dando fe de la existencia de una desviación de la lex artis en el caso concreto. ${ }^{39}$

Con todo, de las distintas apreciaciones que se pueden presentar en relación a la correcta valoración del fenómeno socio-jurídico de la negligencia médica, se advierte que estas distorsiones producen un contexto fáctico de afectación grave en la salud de los pacientes, que ven cómo una mayor responsabilidad del galeno termina por alterar el sistema en su contra. Los autores Sclar y Housman ${ }^{40}$ señalan que sin perjuicio de que la medicina defensiva puede ocasionar algunos efectos beneficiosos al promover más diligencia en la práctica profesional, produce sin lugar a dudas consecuencias perjudiciales en la economía y en la calidad de los tratamientos de salud, esto último sea por brindar demasiado cuidado (medicina defensiva en su modalidad "positiva"), o muy poco (variante "negativa"). Cuando el galeno niega los cuidados debidos a un paciente complejo, de alto riesgo o en un contexto de urgencia, el detrimento en su nivel de bienestar es directo y patente. En el polo opuesto, el tratamiento excesivo puede generar un mayor potencial de error. Así, los estudios han demostrado que aumentar el número de pasos en una terapia multiplica el

\footnotetext{
${ }^{37}$ Sin embargo, dichas limitaciones a los montos de las indemnizaciones por daños no patrimoniales han acarreado como consecuencia no deseada (ni prevista) el que las demandas por daños patrimoniales aumenten, y en igual proporción, las concesiones de los jueces por daño emergente y lucro cesante. Un estudio empírico demuestra este hecho: SHARKEY, Catherine M., "Unintended consequences of medical malpractice caps", New York University Law Review, Vol. 80, n 2, (mayo 2005), pp. 391-512.

${ }^{38}$ SHER, "New differences", cit. nota no 33, p. 6.

${ }^{39}$ Concretamente en la India, la Corte Suprema de dicho país, en sentencia de 5 de agosto de 2005, resolvió que ningún médico podía ser condenado por negligencia médica a menos que exista, prima facie, evidencia, en la forma de una opinión veraz de otro profesional médico, preferentemente perteneciente a una institución gubernamental de la misma área, que ratifique las acusaciones de un acto imprudente. Ver: BHULLAR, Dr. D.S.; GARGI, Dr. J., "Medical negligence", JIAFM, 27 (3), (2005), ISSN: 0971-0973, pp. 195 y ss.

${ }^{40}$ SCLAR/HOUSMAN, "Medical", cit. nota $n^{\circ} 22$, pp. 78-79. Otros han señalado que la evidencia empírica no permite obtener conclusiones categóricas respecto del rol de la medicina defensiva como mecanismo para prevenir accidentes en el rubro de la salud. Sin embargo, indican que sí es posible sostener ciertos efectos benéficos, tales como: una mayor información de los riesgos en los tratamientos y alternativas para pacientes y el surgimiento de programas institucionales para la prevención de accidentes médicos. TREBILCOCK, Michael J.; DEWEES, Donald D.; DUFF, David G., "The medical malpractice explosion: an empirical assessment of trends, determinants and impacts", Melbourne University Law Review, Vol. 17, (diciembre 1990), pp. 539-565, p. 561 .
} 
MARTÍNEZ, Marco. "La graduación del deber de cuidado en el delito culposo por Actos de mala praxis médica: un análisis dogmático, jurisprudencial y económico".

porcentaje de yerros posibles. ${ }^{41} \mathrm{Al}$ practicar demasiados análisis, los médicos pueden terminar lesionando sus pacientes en un intento de tratar problemas que parecieran existir debido a lo que arrojan exámenes falsamente positivos, los cuales son practicados en el cuerpo del sujeto. ${ }^{42}$

Las soluciones que se han propuesto en Estados Unidos ${ }^{43}$ para superar los efectos de la medicina defensiva se pueden resumir en las siguientes:

1.- Limitar los efectos de la responsabilidad civil sobre las economías privadas de los médicos.

2.- Privilegiar la solución alternativa de conflictos.

3.- Traslación de la responsabilidad civil del médico a nivel institucional, empresarial u hospitalario.

4.- Creación de un sistema administrativo selectivo, destinado a resarcir los perjuicios causados a las víctimas de negligencia médica mediante criterios de responsabilidad objetiva.

5.- Establecer guías clínicas como bases para la fijación de estándares de cuidado.

Como veremos infra, en nuestro país la Ley 19.966 publicada en el Diario Oficial de 3 de septiembre de 2004, ya ha incorporado algunas de estas propuestas. Sin embargo, en Chile debemos primero abordar la debida racionalización de los límites entre lo propio del ámbito penal y la sede civil, lo cual ya ha sido superado en la legislación norteamericana y en la mayor parte del Derecho comparado. ${ }^{44}$ La fijación de un modelo de culpa grave para la configuración de una sanción penal por un hecho de imprudencia médica, relegando los supuestos de culpa leve o levísima a un ámbito estrictamente civil, puede atenuar las consecuencias de esta distorsión, especialmente teniendo en cuenta el espíritu del legislador chileno en esta materia, que según veremos en el siguiente apartado, desea otorgar preponderancia al principio de fragmentariedad y no a una expansión punitiva de estos hechos.

\section{El principio de fragmentariedad y de última ratio}

Conforme al denominado principio de fragmentariedad, el Derecho penal no pretende sancionar toda conducta que en principio se presenta como contraria al ordenamiento jurídico general, sino que tan sólo aquellos ataques intolerables sobre bienes jurídicos cuya

\footnotetext{
${ }^{41}$ SCLAR/HOUSMAN, "Medical", cit. nota $n^{\circ}$ 22, pp. 79. El autor cita un estudio del Dr. Lucian Leape, profesor adjunto de la Universidad de Harvard. LEAPE, Lucian, "Error in medicine", Journal of the American Medical Association, 272 (23), (diciembre 1994), pp.1 y ss. Asimismo, referencia un estudio de Julio de 1999 que indica que el $71 \%$ de los médicos que admitían practicar medicina defensiva, señalaban que lo hacían ordenando exámenes adicionales.

${ }^{42}$ SCLAR/HOUSMAN, "Medical", cit. nota ${ }^{\circ}$ 22, p. 79. La figura del personaje televiso "Dr. House" parece ajustarse a esta caracterización.

${ }^{43}$ SCLAR/HOUSMAN, "Medical", cit. nota no 22, pp. 79-82.

${ }^{44}$ En Estados Unidos recurriendo al concepto de "gross negligence". Igual solución se da en la mayor parte de las legislaciones comparadas. Cit. notas $\mathrm{n}^{\mathrm{0}}$ 51-56.
} 
subsistencia o indemnidad se estime como imprescindible para la convivencia social. ${ }^{45}$ En relación directa con esta idea, a modo de fundamentación, el principio de última ratio se traduce en que el Derecho penal responde a una naturaleza subsidiaria o secundaria, en tanto el castigo penal sólo puede aplicarse cuando las soluciones otorgadas por otras ramas del Derecho se nos presentan como insuficientes. Lo anterior, a juicio de Cury, es una expresión de las ideas político criminales modernas inspiradas en el principio de humanidad. $^{46}$

Pues bien, a nuestro juicio la legislación chilena de los últimos diez años ha intentado aplicar los principios de fragmentariedad y de última ratio en sede de mala praxis médica, proponiendo como regla una solución indemnizatoria o de resarcimiento patrimonial para estos supuestos. Esto se puede dilucidar con claridad en una serie de normativas nuevas que han dado lugar a la creación de un sistema cuya conclusión es sin duda aplicación del referido principio de fragmentariedad, y su fundamento, el Derecho penal como última razón.

En primer lugar, con la implementación de la reforma procesal penal, ciertas instituciones nuevas y algunas regulaciones han creado una respuesta de naturaleza meramente reparatoria o indemnizatoria para estos casos. Así, por ejemplo, la posibilidad de que en los delitos culposos, incluso en el cuasidelito de homicidio, pueda recurrirse a la salida alternativa de los acuerdos reparatorios, ${ }^{47}$ extinguiendo con ello la responsabilidad penal de un eventual hecho punible, nos habla de que el espíritu de la ley apunta a una vía indemnizatoria y no punitiva para las negligencias médicas. ${ }^{48}$ Lo mismo cabe para la denominada salida alternativa de suspensión condicional del procedimiento, conforme al artículo 238 letra e) del Código Procesal Penal. ${ }^{49}$ También debemos tener presente que el

${ }^{45}$ CURY, Derecho Penal, cit. nota ${ }^{\circ}$ 8, p.88. En igual sentido: ROXIN, Claus, Derecho Penal: Parte General, Tomo I, Segunda edición, Trad. LUZÓN PEÑA, Diego- Manuel; DÍAZ; GARCÍA CONLLEDO, Miguel; DE VICENTE REMESAL, Javier, Madrid: Civitas, 1997, p. 65; ZAFFARONI, Eugenio Raúl; ALAGIA, Alejandro; SLOKAR, Alejandro, Derecho Penal: Parte General, Buenos Aires: Ediar Sociedad Anónima Editora, 2002, pp.110-139; BUSTOS RAMÍREZ, Juan, Derecho Penal, Parte General, Tomo I, Santiago: Ediciones Jurídicas de Santiago, 2007, pp.369-372.

${ }^{46}$ CURY, Derecho Penal, cit. nota no 8 , pp. 86-87.

${ }^{47}$ Artículo 241 inciso segundo del Código Procesal Penal.

${ }^{48}$ Dicha salida procede sin distinción en relación a la intensidad o grado de negligencia, o sea, sin diferenciar entre una imprudencia leve o grave. Sin embargo, debe tenerse presente que en el proceso penal chileno opera el denominado control horizontal de las pretensiones punitivas, razón por la cual resaltamos que la ley busca solucionar estos casos como regla mediante el resarcimiento civil, presentando la alternativa, sin perjuicio de que los intervinientes - víctima y ministerio público - puedan optar por seguir el curso ordinario del proceso y buscar una pena privativa de libertad para el imputado, si estimaren que la afectación del bien jurídico fue producto de una imprudencia grave, temeraria e injustificable. Lo anterior - en materia de acuerdos reparatorios - es subsumible en el concepto de "interés público prevalente", como límite material a dicha salida alternativa, normado en el artículo 241 del Código Procesal Penal.

${ }^{49} \mathrm{Si}$ bien se advierte que estas soluciones reparatorias se presentan al interior del proceso penal (implican extinguir su responsabilidad penal, sin perjuicio de las consecuencias civiles que pueda tener), y no implican llevar compulsivamente el asunto a sede civil (aunque a juicio de HORVITZ LENNON y LÓPEZ MASLE es factible estipular que el acuerdo reparatorio produzca efectos extintivos respecto de las acciones civiles que se deriven del delito, aun cuando - si nada se acordare en dicho sentido - la regla general sea lo contrario. 
MARTÍNEZ, Marco. "La graduación del deber de cuidado en el delito culposo por Actos de mala praxis médica: un análisis dogmático, jurisprudencial y económico".

legislador ha restringido de manera importante el uso de la acción civil dentro del proceso penal, impidiendo dirigirla en contra de los terceros civilmente responsables y en los procedimientos abreviados y simplificados.

A lo anterior agréguese el hecho que la Ley 19.966 publicada en el Diario Oficial de fecha 3 de septiembre de 2004, ha creado normas especiales de responsabilidad médica aplicables a negligencias ocurridas en el sistema de salud pública. Entre ellas establece en su artículo 38 la responsabilidad del Estado Administrador por los daños causados a los usuarios por falta de servicio, con reglas especiales en materia de resarcimiento; por ejemplo, la fijación de criterios legales expresos para la determinación del daño moral. Asimismo, se establece en su artículo 43 un sistema de mediación obligatoria por parte del Consejo de Defensa del Estado, como requisito previo para poder accionar civilmente en contra de prestadores de salud públicos, suspendiendo durante su trascurso el plazo de prescripción de la acción penal (artículo 45 de la Ley 19.966), propiciando la solución prejudicial de una eventual negligencia por la vía de una transacción sobre los perjuicios padecidos por el paciente, limitando la responsabilidad patrimonial en este caso, estrictamente a nivel institucional, sin perjuicio del derecho de repetición contra el profesional por parte del Estado.

Finalmente, debe tenerse presente que en nuestro sistema punitivo los delitos culposos son por regla atípicos, ${ }^{50}$ lo cual implica que el espíritu del legislador chileno apunta a reservar la sanción penal de hechos culposos a situaciones de relevancia intersubjetiva y grave afectación a bienes jurídicos socialmente valorados, condicionada siempre a un efectivo resultado dañoso por sobre el desvalor de acción, pues se entiende que el ámbito adecuado para esta tipología de situaciones es - en principio - el del Derecho privado.

Esta misma tendencia podemos observar en el Derecho comparado. En el Derecho anglosajón, el límite entre la responsabilidad penal y la civil en materia de medical malpractice se encuentra en el concepto de gross negligence o "culpa grave": ${ }^{51}$ la regla general estará dada por la vía civil, mientras que para recurrir a la penal se requerirá de una negligencia de intensidad. El Derecho norteamericano ha definido dicho estándar como:

HORVITZ LENNON, María Inés; LÓPEZ MASLE, Julián, Derecho procesal penal chileno, Tomo I. Santiago: Editorial Jurídica de Chile, 2002, p. 572), no es menos cierto que constituyen claras manifestaciones de los citados principios de fragmentariedad, necesidad de pena, subsidiariedad, y última ratio a que hemos hecho referencia, pues significan obviar aquella consecuencia que es consustancial al Derecho penal: la pena privativa de libertad. En este sentido: SILVA SANCHEZ, Jesús María, La expansión del Derecho penal. Aspectos de la política criminal en las sociedades postindustriales, Segunda edición, Madrid: Civitas, 2001, pp.151-152.

${ }_{50}$ Articulo $10 \mathrm{n}^{\mathrm{o}} 13$ del Código Penal Chileno. POLITOFF LIFSCHITZ, Sergio; ORTIZ QUIROGA, Luis, Texto y comentario del Código Penal Chileno, Tomo I, Santiago: Editorial Jurídica de Chile, 2002, p. 164.

51 MONICO, Edward; KULKAMI, Rick; CALISE, Arthur; CALABRO Joseph; "The Criminal Prosecution of Medical Negligence", The Internet Journal of Law, Healthcare and Ethics, Vol. 5, no 1, (2007), pp. 1-15, p. 4. 
"That degree of negligence or carelessness which is denominated as gross, and which constitutes such a departure from what would be the conduct of an ordinarily careful and prudent man (...) as to furnish evidence of that indifference to consequences which in some offenses takes the place of criminal intent". ${ }^{2}$

En Francia, la judicatura de ese país ha precisado que se requiere una infracción "grosera" del respectivo deber de cuidado para configurar el tipo culposo por mala praxis médica. Así, la jurisprudencia francesa ha aceptado la responsabilidad del profesional médico cuando éste "revela una ignorancia o una negligencia inadmisible", "demuestra un desconocimiento grosero de su arte" o el error es inexcusable. ${ }^{53}$

Por su parte, en España el nuevo Código Penal de 1995 ha reformado el sistema de delitos culposos médicos, tipificando como delitos sólo las imprudencias graves, mientras que las leves son sancionadas a título de faltas, ${ }^{54}$ constituyen supuestos de acción penal privada y admiten el perdón del ofendido como causal de extinción de responsabilidad penal. ${ }^{55}$

En Argentina, la jurisprudencia también ha seguido el criterio de "culpa grave" para configurar responsabilidad penal médica. Así, la Sala IV de la Cámara Nacional de Apelaciones en lo Criminal y Correccional, ha expresado que "la equivocación diagnóstica es penalmente injustificable si se asienta en error grosero (...)". 56

\footnotetext{
${ }^{52}$ MONICO/KULKAMI/CALISE/CALABRO; "The Criminal”, cit. nota $\mathrm{n}^{\circ}$ 51, p. 4. Sin embargo, un estudio crítico de este concepto se ha hecho presente en el Reino Unido, donde los autores suelen destacar su vaguedad a la hora de su delimitación jurisprudencial, en tanto los casos suelen resolverse en base a elementos netamente subjetivos planteados por fiscales, magistrados y peritos judiciales, proponiéndose incluso la abolición de dicha fórmula. QUICK, Oliver, "Prosecuting "gross" medical negligence: manslaughter, discretion, and the Crown Prosecution Service", Journal of Law and Society, Vol. 33, n 3, (septiembre 2006), pp. 421-450.

${ }^{53}$ CESANO, José Daniel, "Los delitos de homicidio y lesiones imprudentes por mala praxis médica", En: LÓPEZ MESA, Marcelo, (Dir.), Tratado de Responsabilidad médica. Responsabilidad civil, penal y hospitalaria, Bogotá: Editorial Ubijus, Legis Argentina S.A., 2007, pp. 741-742.

${ }^{54}$ SILVA SÁNCHEZ, Jesús María, Medicinas alternativas e imprudencia médica, Ed. Boch, 1999, pp. 20-22.

55 Asimismo, el Código Penal Español contiene un tipo agravado que sanciona el homicidio cometido mediante imprudencia profesional del facultativo, con pena de inhabilitación especial para el ejercicio de la profesión, oficio o cargo, por un período de seis años. HAVA, La imprudencia, cit. nota n ${ }^{\circ} 19$, pp. 21-42. De todas formas, un sector de la doctrina suele señalar que las fronteras entre lo que puede estimarse como "grave" y lo que podría calificarse como "leve" no siempre resultan claras, a pesar de que el Tribunal Supremo Español y algunos autores han dado ciertas luces al respecto, lo cual desarrollaremos en detalle más adelante. SILVA, Medicinas, cit. nota $\mathrm{n}^{\circ} 54$, p. 21.

${ }^{56}$ CESANO, "Los delitos", cit. nota $\mathrm{n}^{\circ}$ 53, p. 742. En Italia, se ha discutido en torno a la aplicación del criterio de "culpa grave" en sede de negligencia médica, a partir del artículo 2236 del Código Civil de ese país que estipula que "si la prestación requiere resolver problemas técnicos de especial complejidad, el prestador no es responsable por los daños, salvo por dolo o negligencia grave". Se ha argumentado por algunos que dicha distinción generaría un efecto discriminatorio en su aplicación en sede penal: GREMBI, Verónica, "Trends and duration of medical malpractice cases. Some evidence from the Italian Court of Cassation decisions (1970-2005)", JEL, (abril 2007), pp. 1-30, p. 9. En: http://ssrn.com/abstract=983039 [visitado el 306-2011].
} 
MARTÍNEZ, Marco. "La graduación del deber de cuidado en el delito culposo por Actos de mala praxis médica: un análisis dogmático, jurisprudencial y económico".

El principio de subsidiariedad implica descartar la criminalización de una conducta lesiva cuando sea posible obtener similares o mejores efectos preventivos del Derecho privado o administrativo, cuyas sanciones de menor afectación de derechos fundamentales deben preferirse a la mayor conculcación que sobre éstos acarrea el Derecho penal. ${ }^{57} \mathrm{Si}$ conjugamos dicha perspectiva con los postulados de fragmentariedad e intervención mínima -que reservan la sanción penal sólo para aquellos ataques de suma gravedad a los intereses esenciales de la colectividad- y constatamos la existencia de todo un marco jurídico extrapenal que ofrece alternativas de tutela eficaz para tales intereses, entonces resulta coherente sostener una limitación al ius puniendi estatal sobre aquel acto dañoso, pero socialmente útil, cuya imputación subjetiva es nimia. Ello por cuanto tales principios responden a decisiones político criminales vinculadas a las consecuencias empíricas del medio de control social alternativo: la efíciencia y eficacia en la consecución de los objetivos de protección y prevención. ${ }^{58}$ Dicho análisis prefiere, en el estudio que nos concierne, la solución reparatoria frente a la pena privativa de libertad, en razón de las repercusiones globales e individuales -tanto en términos de costes económicos como de salud- que acarrea dicho exceso en el celo retributivo del legislador.

\section{Elementos de interpretación}

Según lo dispone el artículo 19 del Código Civil, que consagra el denominado elemento gramatical o literal de interpretación, "las palabras de la ley se entenderán en su sentido natural y obvio", que entre nosotros la jurisprudencia ha entendido como aquél que señala el diccionario de la Real Academia Española de la Lengua. ${ }^{59}$ Complementando dicha norma, el artículo 21 del mismo código señala que "las palabras técnicas de toda ciencia o arte se tomarán en el sentido que les den los que profesan la misma ciencia o arte; a menos que aparezca claramente que se han tomado en sentido diverso", arguyendo la jurisprudencia que para tales efectos ha de entenderse que quienes profesan "la ciencia del Derecho penal" son los autores o la doctrina penal nacional. ${ }^{60}$

Ahora bien, la necesidad de complementar el elemento gramatical con otros recursos hermenéuticos - en el caso de la expresión "negligencia culpable" empleada por el citado articulo 491 del Código Penal - se vuelve imprescindible tanto porque resulta evidente que la ley no ha querido referirse al sentido natural y obvio de dicha expresión, como por el hecho que nuestra misma doctrina no se encuentra conteste sobre cuál es el sentido técnico que ha de tener dicho término. ${ }^{61}$ Ello, en consecuencia, nos permite recurrir a elementos

\footnotetext{
${ }^{57}$ OSSANDÓN WIDOW, María Magdalena, La formulación de los tipos penales. Valoración crítica de los instrumentos de técnica legislativa, Santiago: Editorial Jurídica de Chile, 2009, p. 426-427.

${ }^{58}$ OSSANDÓN, La formulación, cit. nota $\mathrm{n}^{\circ}$ 57, p. 433; 372-373.

${ }^{59}$ ETCHEBERRY ORTHUSTEGUI, Alfredo, El Derecho Penal en la Jurisprudencia, Parte General, Tomo I, Santiago: Editorial Jurídica de Chile, 1987, p. 16.

${ }^{60}$ ETCHEBERRY, El Derecho Penal, cit. nota n ${ }^{\circ}$ 59, pp. 16-17.

${ }^{61}$ ETCHEBERRY, "Tipos penales", cit. nota $n^{\circ} 7, \mathrm{p} .278$, hace patente dicha obscuridad: “(...) el concepto clave para determinar la responsabilidad del médico, conforme al artículo 491 del Código Penal, es el concepto de "negligencia culpable", la expresión utilizada por la ley. ¿Qué quiere decir "negligencia culpable? La expresión culpable no añade en verdad absolutamente nada a la expresión negligencia; dentro
} 
sistemáticos, históricos y teleológicos de interpretación, conforme lo faculta el ya citado artículo 19 del Código Civil. ${ }^{62}$

Los dos primeros han sido invocados por la doctrina chilena mayoritaria para reiterar la tesis del estándar de "culpa leve" como parámetro de diligencia en la materia. Así, el argumento sistemático de graduación invocado por los autores nacionales ${ }^{63}$ parece conjugarse plenamente con el análisis del legislador histórico. Consta en la sesión número 110 de las Actas de la Comisión Redactora del Código Penal, que el artículo 491 no fue tomado del modelo punitivo español, sino que constituye una creación criolla incorporada ante la proposición del comisionado Señor Rengifo, quien estimaba que luego de la redacción y aprobación del título relativo a los cuasidelitos - entre ellos el actual artículo 490 del código - el delito culposo por actos de negligencia médica no había quedado contemplado. ${ }^{64}$ De ello fluiría que la distinción entre las referidas normas se encontraría en la graduación, pues de otra forma no se justificaría la tipificación especial del artículo 491 por sobre la fórmula general de sujeto activo universal del artículo 490, resultando ello en una elevación en términos de exigencias de cuidado para los profesionales de la salud, cuyo fundamento hemos ya revisado. ${ }^{65}$

Este argumento se opone a una interpretación teleológica y axiológica de la norma en cuestión, que valore como telos las implicancias político-criminales de la norma viva y su interacción con los principios fundamentales limitantes del ius puniendi estatal - respetuoso siempre del tenor literal posible del articulado - por sobre una inferencia equívoca de las motivaciones del creador de la disposición, en tanto podemos afirmar, como señala con claridad el profesor Luzón Peña, que "la interpretación histórica no tiene generalmente

del sistema jurídico penal toda negligencia es una forma de culpa, o sea, toda negligencia es culpable. A lo más, pero siempre con bastante imprecisión, podría establecerse una especie de comparación o paralelo con los otros dos artículos, entre los cuales está insertado este de los médicos". De todas formas, el elemento literal, a juicio de BUSTOS RAMÍREZ, juega a favor de nuestra interpretación, pues destaca dicho autor que el artículo 492 (en relación al cual existe acuerdo que exigiría "culpa leve". GARRIDO, Derecho Penal, cit. nota $n^{\circ} 3$, pp. 223 - 224.) emplea la expresión "mera", a diferencia del artículo 491, lo cual da a entender la exigencia de un criterio opuesto. Asimismo, el artículo 491 agrega la fórmula "culpable", lo que en su concepto evidentemente equivale a "inexcusable", términos que no estarían utilizados en sentido dogmático sino vulgar, esto es, constitutivos de un descuido temerario sin poder dar la más mínima explicación al respecto. BUSTOS, El delito, cit. nota ${ }^{\circ}$ 4, p. 56.

${ }^{62}$ POLITOFF/MATUS/RAMÍREZ, Lecciones, cit. nota ${ }^{\circ} 4$, p. 111.

${ }^{63}$ Resaltado por GARRIDO, Derecho Penal, cit. nota n ${ }^{\circ}$. Asimismo, ver cit. notas n 2, 3, 4, 5 y 6 .

${ }^{64}$ CAMPOS QUIROGA, Jaime A., "La responsabilidad de carácter culposo", Revista de Ciencias Penales, tomo XXXVII, (1981), pp. 107-129, p. 118, en referencia a la sesión $n^{\circ} 110$ de las Actas de la Comisión Redactora que consigna que "Se hizo notar en seguida, un vacío respecto de los perjuicios que ocasionaban los médicos, cirujanos, farmacéuticos, etc., por su descuido o negligencia culpable. A indicación del Sr. Rengifo, se resolvió considerar este caso como un cuasidelito, agregándolo como inciso del 477 cuando cause daño a las personas y como falta si no concurren estas circunstancias, considerándose este segundo caso como un nuevo inciso del 479".

${ }^{65}$ CAMPOS, "La responsabilidad”, cit. nota n ${ }^{\circ} 64$, p. 119. 
MARTÍNEZ, Marco. "La graduación del deber de cuidado en el delito culposo por Actos de mala praxis médica: un análisis dogmático, jurisprudencial y económico".

carácter decisivo, pues ya hemos visto que sobre ella domina la interpretación objetiva del sentido y finalidad de la ley en el momento actual (...)" ${ }^{66}$

La valoración de las implicancias descritas supra, se traduce en ponderar consideraciones de racionalidad económica como elemento hermenéutico válido a aplicar sobre la disposición del artículo 491 del Código Penal Chileno. Para ello, sin embargo, es necesario previamente dar un paso adicional más allá de su entendimiento como recurso catalizador de políticas criminales a nivel de órganos de decisión ${ }^{67}$ e innovar en su utilización ahora como instrumento de interpretación dogmático. ${ }^{68}$

La aplicación de criterios de asignación eficiente de recursos a objeto de fijar el sentido y alcance de una disposición penal, significa reconocer - tal como lo señala Paredes Castañón ${ }^{69}$ - que dicha labor requiere siempre de elementos de juicio no derivables de la norma misma, sino que fundamentada en argumentaciones autónomas de carácter racional, coherentes con el ordenamiento jurídico, adaptables a la realidad social impuesta, susceptibles de brindar soluciones que - enmarcadas en los principios rectores de una determinada política social - valoren las consecuencias de dichas decisiones, de modo que no sólo reconozcan su adecuación formal al texto legal, sino que también brinden respuestas efectivas a las necesidades interpersonales que subyacen a las mismas. ${ }^{70}$ Así, las decisiones conforme a Derecho han de ser racionales no sólo desde una perspectiva lógico - sistemática - formal, sino que también desde un prisma teleológico: factibles y eficientes, adecuando los medios a los recursos existentes. ${ }^{71}$

Lo anterior no implica desconocer que el límite de toda tarea interpretativa se encuentra en el denominado "tenor literal posible", ${ }^{72}$ marco al cual toda decisión judicial debe ceñirse, conforme a las directrices del principio de reserva o legalidad. Dicho tenor literal del tipo penal viene a fijar los objetivos últimos del dictamen: la tutela del bien jurídico y el respeto por los valores superiores del ordenamiento. Lo demás, es decir, los medios que han de emplearse para obtener dichos objetivos, pertenece a lo que Paredes Castañón denomina "perspectiva de eficiencia", esto es, correcciones estratégicas, en términos de racionalidad,

${ }^{66}$ LUZÓN PEÑA, Diego Manuel, Curso de Penal: Parte General, Madrid: Editorial Universitas, 2002, p. 167.

${ }^{67}$ En este sentido: BECKER, Gary, "Crime and Punishment", JPE, Vol. 4, (1968), pp. 169 - 217.; POSNER, Richard A., "A Theory of Negligence", The Journal of Legal Studies, Vol. 1, n¹, (enero 1972), pp. 29-96. En: http://www.jstor.org/stable/72401, [visitado el 3-06-2011]; STIGLER, George J., "The optimum enforcement of laws", JPE, Vol. 78, (mayo-junio 1970), pp. 526-536.

${ }^{68}$ PAREDES CASTAÑÓN, José Manuel, "El límite entre imprudencia y riesgo permitido en el Derecho penal. ¿Es posible determinarlo con criterios utilitarios?", $A D P C P$, t. XLIX, fasc. III, (septiembre-diciembre 1996), pp. 909-942.

${ }^{69}$ PAREDES, "El límite", cit. nota n ${ }^{\circ} 68$, p. 912

${ }^{70}$ PAREDES, "El límite", cit. nota n 68, p. 915

${ }^{71}$ PAREDES, "El límite", cit. nota n ${ }^{\circ} 68$, p. 923.

${ }^{72}$ MATUS ACUÑA, Jean Pierre, La ley penal y su interpretación, Santiago: Editorial jurídica "Congreso", 1994, pp. 210-213. Sobre el particular ver: MERA FIGUEROA, Jorge, Derechos humanos en el Derecho penal Chileno. LexisNexis, 1998, pp. 62-92; LUZÓN PEÑA, Diego- Manuel, Curso de Derecho Penal: Parte General, Editorial Universitas, 2002, pp. 81, 165. 
destinadas a lograr dichos fines. ${ }^{73}$ Desde dicha óptica podemos sostener que cada vez que tales objetivos de justicia buscados por la norma punitiva no aparecen mermados de manera sustancial, resulta válido recurrir a argumentaciones teleológicas o instrumentales para solucionar dilemas interpretativos, centrando la cuestión en el quid fundamental propio de todo análisis jurídico-económico en esta materia: la eficiente y racional distribución de costes entre los sujetos que intervienen en el conflicto penal. ${ }^{74}$

Como es sabido, tradicionalmente dicha cuestión ha sido resuelta equiparando los factores de imputación a la asunción total de todos los costes del conflicto penal. ${ }^{75} \mathrm{Sin}$ embargo, la búsqueda de un paradigma que resulte globalmente más eficiente resulta justificable, por cuanto, como se ha observado, ${ }^{76}$ un sistema que exija de los ciudadanos adoptar medidas de cuidado que impliquen una eliminación de todo riesgo resultaría en una paralización insostenible de una serie de actividades consideradas hoy como socialmente imprescindibles. ${ }^{77} \mathrm{Ha}$ de buscarse por consiguiente, en base a elementos de imputación fundados en fórmulas de riesgo permitido y la fijación interpretativa de baremos de cuidado, aquel modelo más cercano al óptimo de eficiencia social en cuanto a distribución de costes entre la colectividad y los sujetos involucrados, el cual devendrá de aquel escenario en el que no sea posible incrementar más el nivel de tutela del bien jurídico sin que los costes de dicho incremento (reducción, cualitativa o cuantitativa, de la actividad peligrosa pero socialmente útil) sean superiores a los costes generados por el riesgo que amenaza de no incrementarse la protección. ${ }^{78}$

En términos de análisis económico, la fórmula del juez Learned Hand del Derecho Anglosajón nos señala que existe negligencia si el daño que irroga el acto (probabilidad y magnitud de la pérdida o daño: $P L$ ) supera el coste de las medidas de protección que han de adoptarse por el autor del hecho para evitar dicho daño $(B)$, en definitiva cuando $P L>B .{ }^{79}$

\footnotetext{
73 PAREDES, "El límite", cit. nota $n^{\circ}$ 68, p. 919. Como bien observa dicho autor, dado que resulta poco frecuente que el sentenciador no respete dichos objetivos mínimos - pues su observancia proviene del seguimiento formal de las normas básicas de interpretación judicial, sin perjuicio de los controles recursivos que el sistema jurídico proporciona a lo intervinientes - las dificultades se plantean justamente en aquella "zona gris" intermedia que no implica un desconocimiento de los objetivos fundamentales de justicia contenidos en la norma, permitiendo así la utilización de criterios de eficiencia en la hermenéutica de la disposición.

${ }^{74}$ PAREDES, "El límite", cit. nota n 68, pp. 923-924.

75 PAREDES, "El límite”, cit. nota n 68, pp. 925-926. Así, se entiende que -en principio - aquel sujeto que aporta los elementos causales de un resultado típico habrá de responder - y asumir los costes de dichas consecuencias - por aquellos resultados que le fueren previsibles, o en caso que fueren dolosos, hubiese querido.

${ }^{76}$ Sobre el particular: BUSTOS, El delito, cit. nota ${ }^{\circ}$ 4, p. 12-13.

${ }^{77}$ PAREDES, "El límite", cit. nota n 68, p. 927. También en dicho sentido: CURY, Derecho Penal, cit. nota $\mathrm{n}^{\circ} 8$, p. 332. Ello justifica en nuestra legislación - como en general en el Derecho comparado - la reticencia del legislador a sancionar los ilícitos culposos, como se colige de la formula general de atipicidad contenida en el artículo $10 \mathrm{n}^{\circ} 13$ del código de castigo chileno.

${ }^{78}$ PAREDES, "El límite", cit. nota n 68, pp. 930-931.

${ }^{79}$ POSNER, "A Theory", cit. nota $\mathrm{n}^{\circ}$ 67, p. 32. La fórmula nació de un caso jurisprudencial sobre responsabilidad extracontractual o torts, "United States vs. Carroll Towing Co.”, F. 2d, 169. Ver también: FLETCHER, George P., Basic Concepts of Criminal Law, New York: Oxford University Press, 1998, p. 115.
} 
MARTÍNEZ, Marco. "La graduación del deber de cuidado en el delito culposo por Actos de mala praxis médica: un análisis dogmático, jurisprudencial y económico".

Complementando esta idea, Posner explica que el nivel de cuidado óptimo será aquél que logré minimizar la suma de los costes del posible accidente $(P L)$ y los costes de prevención del accidente $(B)$, esto es, cuando una variación de $B$ logre reducir $P L$ en la misma proporción. $^{80}$

Ahora bien, cuando el coste neto que sufre quien causa el daño - en razón de la sanción legal que se impone - resulta superior al coste social de su conducta y al óptimo normativo necesario para la prevención de los efectos del acto riesgoso, se produce lo que los economistas denominan "overenforcement" 81 Como resulta evidente, ello no siempre resultará injusto, y en algunas ocasiones incluso no acarreará consecuencias negativas en el sistema, especialmente cuando el hecho dañoso en sí no genera mayor utilidad social (v.g.: delito de violación). Sin embargo, cuando las actividades asociadas a éste sí la producen, y los actores del sistema perciben que existe una probabilidad cierta, realista y recurrente de que una conducta sea sancionada con overenforcement, con el consecuente efecto negativo extrajurídico sobre su posición financiera o personal (definitional spillover $^{82}$ ), se produce la figura estrechamente vinculada a la anterior: overdeterrence, esto es, una modificación en la conducta de los actores del sistema vinculada a una apreciación ex ante respecto de un escenario racionalmente adverso. ${ }^{83}$

En términos simples, ello implica que el individuo sólo desempeñará la actividad riesgosa pero socialmente útil - cuando el beneficio esperado $(b)$ sea mayor que el castigo óptimo para prevenir el comportamiento no deseado (x) sumado a los efectos perjudiciales que le acarrea la retribución excesiva (y) o definitional spillover (en definitiva: $b>x+y$ ). Pero por el contrario, se abstendrá de actuar cuando $x<b<x+y$, resultando que el exceso en la sanción acarrea un detrimento colectivo ineludible. ${ }^{84}$

Aplicando la fórmula de Learned Hand, $\operatorname{Posner}^{85}$ señala que una conducta imprudente requerirá tipificación penal, superando la necesidad de limitarla sólo a la contravención civil, cuando se reúnan los siguientes requisitos copulativos:

El enunciado ha sido recogido por el artículo 2.02 (2) (d) del Model Penal Code de Estados Unidos, en tanto la jurisprudencia norteamericana lo ha empleado para interpretar el concepto de "substantial and unjustified risk", identificando los costes con el riesgo injustificado y los beneficios con las razones que tienen los ciudadanos para asumir dichos riesgos.

${ }^{80}$ POSNER, Richard, Economic Analysis of the Law, Seventh edition, New York: Aspen Publishers, Wolters Kluwer Law \& Business, 2007, p. 168, nota al pie de página $\mathrm{n}^{\circ} 2$.

${ }^{81}$ BIERSCHBACH, Richard A.; STEIN, Alex, "Overenforcement", The Georgetown Law Journal, Vol. 93:1743, (2005), pp. 1744-1745.

${ }^{82}$ Los efectos de un definitional spillover se desprenden de aquellas conductas formalmente contempladas en la hipótesis legal, pero que son contrarias al objeto, espíritu o ratio legis de la norma. BIERSCHBACH/STEIN, “Overenforcement”, cit. nota ${ }^{\circ}$ 81, p. 1755. En nuestro análisis: Los costes que sobre el galeno genera un baremo de cuidado por sobre el estándar de salud propio del área, en términos de los efectos extrajurídicos que le acarrea la responsabilidad penal y civil por acto médico negligente. V.g: sobre su prestigio profesional.

${ }^{83}$ BIERSCHBACH/STEIN, “Overenforcement”, cit. nota ${ }^{\circ} 81$, p. 1748.

${ }^{84}$ BIERSCHBACH/ STEIN, “Overenforcement”, cit. nota n 81, pp. 1748-1749.

${ }^{85}$ POSNER, Economic, cit. nota ${ }^{\circ} 80$, p. 236-237. 
1.- Que el valor de $P L$ (probabilidad y magnitud del daño) sea mayor que $B$ (costes de las medidas de prevención que ha de adoptar el autor del hecho para prevenir el daño).

2.- Que el valor de $L$ (magnitud del daño) sea alto.

Posner fundamenta su conclusión en tanto si $B$ y $P L$ se aproximan, aumenta el riesgo de sancionar erróneamente al autor del daño culposo, contingencia que se magnifica si la responsabilidad que se ha de imponer es de naturaleza penal, un razonamiento que parece considerar tanto la asignación eficiente de recursos sociales como también los principios cardinales de subsidiariedad y fragmentariedad. Así, el autor estima que incluso si $B$ es mucho menor que $P L$, a menos también que el valor de $L$ sea alto, no se ve razón alguna para no sancionar el hecho únicamente a nivel de responsabilidad civil extracontractual, fijando el límite entre ambas sedes en el concepto de "reckless and grossly lifeendangering conduct" o culpa grave. ${ }^{86}$

Una mayor intensidad en la imputación subjetiva del acto podría justificar el uso del Derecho penal por sobre una respuesta meramente administrativa o privada. ${ }^{87}$ Ello ya que la presencia de dolo o culpa grave aumenta la probabilidad $(P)$ de que efectivamente ocurra el hecho lesivo. Asimismo, puesto que es más probable que el autor doloso, y no el simplemente negligente, tome medidas para evitar que se descubra el ilícito perpetrado, será necesario que sean agentes del Estado, y no los particulares, quienes adquieran información e investiguen el hecho intencional. Finalmente, una mayor culpa o dolo puede afectar la disposición del autor para transar con la víctima, haciendo necesaria, para fines de prevención, una sanción que sólo el Derecho Penal puede brindar. ${ }^{88}$ Desde esta óptica, castigar la negligencia médica con culpa leve no parece adecuarse a los criterios de

\footnotetext{
${ }^{86}$ POSNER, Economic, cit. nota no 80, p. 237.

${ }^{87}$ SVATIKOVA, Katarina, "Economic criteria for criminalization: Why do we need the Criminal Law?", Rotterdam Institute of Law and Economics (RILE), Working Paper Series, $\mathrm{n}^{\circ}$ 2008/12, marzo 2009, p. 1-28, p. 5. En: http: //ssrn.com/abstract=1150689. [visitado el 3-06-2011].

${ }^{88}$ SVATIKOVA,"Economic", cit. nota n ${ }^{\circ}$ 87, p. 6. Asim|ismo, se menciona la baja probabilidad de detección como un elemento que incide en la decisión político criminal de penalizar una conducta. Así, Becker señalaba que se disuade y previene una conducta dañosa si los probables costes de la infracción superan sus beneficios. Dichos costes se determinan por la intensidad de la retribución esperable, que a su vez se define como la probabilidad de detección del delito multiplicado por la gravedad de la pena. Por tanto, la sanción óptima debe ser mayor si la probabilidad de detección es baja. BECKER, "Crime", cit. nota no , 67, p. 174-180. El Derecho penal resulta idóneo para tal finalidad, pues puede imponer sanciones más rigurosas que el Derecho privado o administrativo. Sin embargo, en los delitos culposos, la posibilidad de detección del ilícito por lo general será alta, pues la víctima usualmente esta presente, conoce la identidad del autor y posee incentivos para denunciar (demandar reparación pecuniaria). SVATIKOVA, "Economic", cit. nota no 87, p. 10. Otros factores de tipificación, tal como el "estigma" que trae aparejada la pena, puede traer efectos indeseados al favorecer la reincidencia en ciertos casos. SVATIKOVA, "Economic", cit. nota $n^{\circ}$ 87, p. 26. Con todo, utilizar el Derecho punitivo para obtener una mayor reprobación social de una conducta y realzar así la adherencia ciudadana al bien jurídico conculcado, implica acentuar un rol simbólico de la pena, cuestión que resulta de cuestionable legitimidad y contrario a los postulados de subsidiariedad, al volverse ésta un instrumento de transformación social que "ya no constituye la última ratio sino la primera". OSSANDÓN, $L a$ formulación, cit. nota $\mathrm{n}^{\circ} 57$, p. 430.
} 
MARTÍNEZ, Marco. "La graduación del deber de cuidado en el delito culposo por Actos de mala praxis médica: un análisis dogmático, jurisprudencial y económico".

racionalidad propios de una legislación que pretenda un mayor bienestar con un menor coste social. ${ }^{89}$

En este sentido, siguiendo a Calabresi, podemos afirmar que todo sistema normativo integral sobre accidentes debe apuntar a la reducción de los costes que éstos causan entre sus objetivos definidores ${ }^{90}$. Ello significa buscar disminuir no sólo el número y gravedad de los hechos dañosos, sino también los costes sociales y administrativos de los mismos, ${ }^{91}$ concepto que conjuga la función preventiva de la pena, en su modalidad especial y general, ${ }^{92}$ con el estudio de la dinámica económica de los incentivos y elecciones del hombre como maximizador de beneficios.

Dicha perspectiva sostiene como presupuesto que la cuestión subyacente a una normativa sobre accidentes es de naturaleza recíproca. Así, en su ya clásico trabajo de 1960, The problem of social costs, Richard H. Coase explicaba que:

"The question is commonly thought of as one in which A inflicts harm on B and what has to be decided is: how should we restrain $\mathrm{A}$ ? But this is wrong. We are dealing with a problem of reciprocal nature. To avoid the harm to B would be to inflict harm on A. The real question that has to be decided is should A be allowed to harm B or should B be allowed to harm $\mathrm{A}$ ? The problem is to avoid the more serious harm. ${ }^{.93}$

En Chile, la medicina defensiva constituye una alteración en las estructuras de comportamiento colectivo del cuerpo médico, overdeterrence que conforme nuestra legislación positiva actual debe tener presente los mayores costes que irrogan a la sociedad los efectos de las políticas públicas de persecución penal ${ }^{94}$, en relación a las demás formas

${ }^{89}$ OSSANDÓN, La formulación, cit. nota $n^{\mathrm{o}} 57$, p. 428.

${ }^{90}$ CALABRESI, Guido, The Costs of Accidents, A Legal and Economic Analysis, Student Edition, New Haven and London: Yale University Press, 1970, pp. 26-30.

${ }^{91}$ Denominada por Calabresi como "función preventiva primaria" (primary cost reduction), la que se obtiene mediante la "prevención general o el mecanismo de mercado" (general deterrence or market approach) o la "prevención especial o sistema colectivo" (specific or collective deterrence), CALABRESI, The Costs, cit. nota $\mathrm{n}^{\circ} 90$, pp. 68-129.

${ }^{92}$ SILVA SÁNCHEZ, Jesús María, Aproximación al Derecho Penal Contemporáneo, Barcelona: J.M. Bosch, 2002, p. 211-238

93 "La pregunta es normalmente pensada como una en que A daña a B y lo que debe decidirse es: cómo controlar a A? Pero es equivocado. Estamos tratando con un problema de naturaleza recíproca. El evitar el daño a B sería el infringirle daño a $\mathrm{A}$. La pregunta verdadera que debe decidirse es ¿debería permitírsele a $\mathrm{A}$ dañar a B o debería permitírsele a B dañar a A? El problema es evitar un daño más grave." COASE, Ronald H, "The Problem of Social Costs", Journal of Law and Economics, Vol. 3, (octubre, 1960), pp.1-23, p. 1.

${ }^{94}$ BECKER, "Crime", cit. nota no 67, p.11-12. Puesto que, tal como señala Becker, "punishments affect not only offenders but also other members of society", un modelo penal de óptima eficiencia confiere prioridad a la pena de multa por su efecto paliativo sobre los costes sociales del ilícito (el coste social de la pena, según BECKER, equivale al coste que irroga el ofensor, sumando o restando el que irroga a terceros, según la naturaleza corporal o pecuniaria de la sanción. BECKER, "Crime", cit. nota $\mathrm{n}^{\circ}$ 67, p. 49.), cuestión que ciertamente no es aplicable al delito culposo al no asociarse su configuración típica con una pena de multa en nuestra legislación, sino con una retribución corporal privativa de libertad (con la consecuente generación de gastos a la sociedad en términos de solventar cárceles, gendarmes, alimentación, operadores del sistema, 
y alternativas de resolución de conflictos que proporciona el sistema. El escenario actual resulta en un aumento drástico del valor de $B$ para buscar disminuir $P L$ en la fórmula de Hand - los elevados costes de las medidas de protección que deben adoptar los profesionales de la salud para evitar accidentar a sus pacientes - equiparándose o incluso pudiendo superar $B$ el nivel de $P L$, sin perjuicio de que en nuestro estudio $L$ siempre será alto tratándose de las hipótesis de lesiones u homicidio que pueden llegar a configurarse del artículo 491 del Código Penal. La concurrencia de sólo uno de los requisitos exigidos por Posner para la tipificación de las negligencias médicas ${ }^{95}$ - en un contexto normativo que sanciona conductas $P L=o ́ \delta$, donde una variación en la intensidad de la imputación subjetiva incide en $P$ - significa que bastaría el resarcimiento patrimonial civil para satisfacer los intereses individuales y colectivos en juego. Ello sin perjuicio que el aumento de $B$ puede incluso alzarse como uno de los factores causantes de un eventual alza mayor de $P L$, distorsión nociva que pudimos constatar supra, ${ }^{96}$ al estudiar los dañinos efectos que puede acarrear la medicina defensiva - tanto en sus modalidades "positiva" como "negativa" - en la salud de los usuarios del sistema.

La interpretación de la disposición penal a la luz de postulados de eficiencia económica es empleada en el presente trabajo como correctivo complementario, en tanto entendemos que una hermenéutica orientada a las consecuencias resulta secundaria frente a los principios de naturaleza deontológica que caracterizan al Derecho penal, los cuales poseen autonomía respecto de la satisfacción de resultados. ${ }^{97} \mathrm{Sin}$ embargo, nuestra propuesta no parece

tratamientos de resocialización, etc.), todo lo cual se resuelve - en cambio - con una preferencia por soluciones reparatorias por sobre las estrictamente punitivas en esta materia. Destacando las consecuencias económicas del delito: MATUS ACUÑA, Jean Pierre, "El Ministerio Público y la política criminal en una sociedad democrática", en: .AA.VV, Delito, pena, y proceso, Santiago: Editorial Jurídica de Chile, 2008, pp. 97-110.

${ }^{95}$ Posner requiere la concurrencia copulativa de $P L>B$, junto a un alto valor de $L$ para tipificar penalmente una conducta. Cit. nota $\mathrm{n}^{\circ} 86$.

${ }^{96}$ Cit. nota $\mathrm{n}^{\circ} 42$.

${ }^{97}$ OSSANDÓN, La formulación, cit. nota ${ }^{\circ}$ 57, p. 376. Citando a Max Weber, Ossandón Widow señala que frente a la racionalidad instrumental (perspectiva de eficiencia), el Derecho penal debe legitimarse por la racionalidad valórica, ya que los resultados eficientes no equivalen necesariamente a los mejores (pueden entrar en conflicto con la justicia, equidad, seguridad, y solidaridad), y por ende no siempre deben ser preferidos. Esta idea de la dogmática continental - en el sentido que la eficiencia sólo puede emplearse como instrumento correctivo y secundario frente a los principios que definen los objetivos del Derecho penal - ya había sido reconocida por los mismos fundadores del análisis económico del Derecho. Así, el mismo Posner explica que existen muchos comportamientos económicamente eficientes, que sin embargo intuitivamente debiesen ser - y son - sancionados, v.g.: permitir pactos suicidas; permitir que bebés sean vendidos para adopción; permitir la discriminación racial, religiosa y sexual para fines privados; legalizar la extorsión; forzar las confesiones autoincriminatrorias; permitir la tortura del imputado para obtener información; otorgarle al condenado la posibilidad de elegir entre cumplir la condena o participar en experimentos científicos peligrosos; etc. Con lo cual el autor reflexiona que "Evidently there is more to justice than economics (...)". POSNER, Economic, cit. nota $n^{\circ} 80$, p. 27. Una crítica a las pretensiones del análisis económico del Derecho puede verse en: BRADLEY, Gerard V., "Overcoming Posner", Michigan Law Review, Vol. 94, nº 6, (mayo 1996), pp. 1-18. Este autor explica que el razonamiento económico es de tipo instrumental, el cual no puede ser utilizado para algún uso humano sin algún tipo de opción valórica previa. Así, Bradley señala que: "You can ask, and economics will help you, (for) the most efficient way to produce poisonous gas, as well as to build a hospital. Economics will not ask and cannot tell you why you should". 
contrariar tales principios y valores fundamentales de un Derecho penal de corte liberal, toda vez que subordina la aplicación de la norma a criterios de subsidiariedad, necesidad de pena, mínima intervención, fragmentariedad, y última ratio, sin conculcar la perspectiva de justicia y retribución, en tanto exigir un baremo de gravedad en la sanción punitiva del delito culposo médico brinda una respuesta eficaz y adecuada a la tutela del bien jurídico garantizando la vigencia efectiva de la norma - lo cual se demuestra no sólo de la revisión integral del sistema jurídico que rige la responsabilidad médica ${ }^{98}$-a nivel civil, procesal y administrativo- sino que también por la reciprocidad e interdependencia que acarrea la distribución de costes entre los sujetos que intervienen en el conflicto penal, lo que resulta en una reformulación refleja de los objetivos, motivación y ratio legis de la incriminación punitiva que contiene el artículo 491 del Código Penal. ${ }^{99}$

\section{El baremo de culpa grave en los delitos culposos por actos de negligencia médica}

Desde la recepción de la doctrina penal de los prácticos italianos, ${ }^{100}$ la graduación de la culpa en lata, levis y levissima ha gobernado la ciencia jurídica punitiva comparada de la primera mitad del siglo veinte. La extracción de esta diferenciación de intensidad en la imputación de la culpa, desde las fuentes del Derecho Romano hacia el Derecho Civil -

${ }_{98}^{98}$ El cual se detalló supra en el apartado 3 del presente trabajo.

99 Adicionalmente, a nivel interpretativo podemos señalar que una posible objeción en contra de esta tesis puede sostenerse en el sentido que implicaría un trato desigual e inexplicablemente más beneficioso en favor del galeno, que realiza una actividad profesional en la cual el contexto de confianza (posición de garante) aumenta la creación de un riesgo penalmente relevante, en perjuicio de otros posibles creadores de riesgos, por ejemplo, del conductor del tráfico rodado, que responde conforme al artículo 492 por culpa leve. Frente a dicha representación, cabe tener presente que el plus de exigencia que viene dado por el artículo 492 del Código Penal, deriva de la adición de un elemento que no prevé el artículo 491: la infracción de reglamentos. Este requisito agregado viene por sí, a fijar un baremo más elevado que el previsto en los artículos 490 y 491. Asimismo, no hay desviación alguna del principio de igualdad, por cuanto existe acuerdo en que el mismo médico, puede también incurrir en la hipótesis prevista en el artículo 492, si es que se configuran los elementos exigidos por el tipo penal. (BUSTOS, El delito, cit. nota n ${ }^{\circ}$, pp. 51-53.) Piénsese por ejemplo, en el médico que infringiendo culposamente los reglamentos y normativa interna del Hospital en el cual labora, causa la muerte de un paciente. Lo que ocurre es que el artículo 491, temperando las exigencias de previsión, no establece una fuente formal del cuidado debido, remitiéndose de manera implícita, al menos en materia médica, a la denominada lex artis ad hoc, que constituye un concepto fluctuante, en continua revisión y cambio, en ocasiones extremadamente impreciso. Por tanto, es incorrecto fijar una medida similar entre el artículo 492, que requiere la infracción de reglas previas, claras y precisas que debe conocer el autor, y el parámetro del artículo 491 del Código Penal, que hace una remisión necesaria, por razones de técnica jurídica, a un concepto volátil, no necesariamente formal. En este sentido CESANO, "Los Delitos", cit. nota n ${ }^{\circ} 54$, p. 717, explica que los delitos culposos, por su carácter de tipos abiertos, significan una necesaria merma al principio de legalidad y taxatividad. Ahora bien, si sostenemos que nuestra legislación pide un estándar superior sólo para los médicos y demás profesionales de salud indicados en el artículo 491, no se ve razón por la cual no debiese exigirse semejante baremo para la infinita gama de profesiones u oficios que también generan una confianza cualificada en terceras personas, inhibiendo su actuación e incrementando el riesgo consiguiente. Ello implicaría, entonces, una vulneración del denominado principio de igualdad por ausencia de un debido elemento de relevancia - tertium comparationis - para efectuar el distingo. Ver OSSANDÓN, La formulación, cit. nota ${ }^{\circ} 57, \mathrm{pp} .444-445$.

${ }^{100}$ CARRARA, Franceso, Programa de Derecho Penal, Parte General, Vol. I., Bogotá-Buenos Aires: TemisDepalma, 1977, pp. 145-146. 
principalmente - ha pasado desde entonces a ser patrimonio común de la dogmática, que ha pretendido aplicarla sobre las modalidades de tipos culposos, normas que por lo general no recogen esta graduación en los textos legales incriminatorios. Es así como -entre nosotrosdicha distinción no tiene consagración expresa en los artículos 490, 491 y 492 del Código Penal, pero se ha entendido que una escala de intensidad en los baremos de cuidado, semejante a la prevista en el artículo 44 del Código Civil, es posible de aplicar en estos casos a efecto de brindar un sentido orientador a las expresiones contenidas en tales disposiciones. ${ }^{101}$

La escala diferenciada de culpa, pese a sus críticas, ${ }^{102}$ nos parece relevante no sólo por cuanto constituye una tradición jurídica centenaria asentada en nuestra doctrina y enquistada en el uso diario de los operadores del sistema, sino también por cuanto invocando dicha graduación podemos crear un segundo filtro de fragmentariedad en la configuración del tipo culposo, examen que responde a criterios de necesidad de pena y los principios de última ratio y subsidiariedad, directrices gobernantes de un Derecho penal de corte liberal respetuoso de los límites materiales del ius puniendi estatal. ${ }^{103}$ Lo anterior como ya apuntamos supra - conduce asimismo a las consecuencias favorables que derivan de un modelo que apunte hacia una asignación eficiente de los recursos sociales, en términos de distribución racional de costes entre los sujetos que intervienen en el conflicto penal subyacente.

${ }^{101}$ Supra cit. nota $\mathrm{n}^{\mathrm{o}} 2,3,4,5$ y 6.

${ }^{102}$ Un importante sector doctrinal estima que dicha graduación carece de importancia. Así, ya en 1950 Jiménez de Asúa señalaba que la citada escala diferenciada de imputación, tomada del Derecho Civil, era totalmente irrelevante, y a lo sumo podía tener implicancias en la intensidad de la pena aplicable, por cuanto era imposible en la práctica hallar una línea divisoria entre la culpa grave y la culpa leve. Para tal efecto, el autor ejemplifica efectuando un detallado estudio de la jurisprudencia del Tribunal Supremo Español, demostrando que sus sentencias no logran establecer una diferencia conceptual. Ver JIMÉNEZ DE AZÚA, Luis, Tratado de Derecho Penal, Tomo V, Sao Pablo: Editorial Losada, 1990, p. 982. En igual sentido, en Chile, NOVOA, Derecho Penal, cit. nota $\mathrm{n}^{\circ}$ 10, p. 509. Más recientemente, Claus Roxin ha seguido este criterio señalando que "el concepto jurídico civil de imprudencia grave resulta poco fructífero para el Derecho penal". Ello fundamentalmente por cuanto a su juicio dicho concepto no ha adquirido contornos claros ni siquiera en el Derecho civil, y en segundo lugar, pues el Derecho penal debe tener en cuenta la incapacidad personal en mucho mayor medida que el Derecho civil. ROXIN, Derecho Penal, cit. nota ${ }^{\circ} 45$, p. 1025. También en este sentido, SILVA SÁNCHEZ, Jesús María, "Aspectos de la responsabilidad penal por imprudencia del médico anestesista, La perspectiva del Tribunal Supremo", DS, Vol. 2, (enero - diciembre 2004), pp. 45-47, estima - en referencia a los límites entre imprudencia temeraria y simple, citando un fallo del Tribunal Supremo Español - que éstos son "tenues y no acentuadamente acusados", siendo difícil encontrar criterios de diferenciación más allá de fórmulas vacías de significación para el caso concreto (vulneración de las más elementales medidas de precaución o el no empleo del cuidado de un hombre mínimamente razonable), aunque admite su importancia práctica y da ciertas luces sobre pautas jurisprudenciales y conceptuales de cotejo.

${ }^{103}$ En este sentido, en Argentina, Marco Antonio Terragni ha señalando que si bien la graduación de la culpa no ha sido recepcionada en el Código Penal de su país, "tampoco ésta desprovista de todo significado. No solamente tiene importancia en la individualización de la pena, (...), sino que también marca la necesidad de descartar como punibles casos en que la imprudencia o negligencia han sido tan insignificantes que no pueden racionalmente fundar un reproche", TERRAGNI, Marco Antonio, El delito culposo, Santa Fe: RubinzalCulzoni, 2003, p.28. 
MARTÍNEZ, Marco. "La graduación del deber de cuidado en el delito culposo por Actos de mala praxis médica: un análisis dogmático, jurisprudencial y económico".

El concepto de culpa grave en materia de responsabilidad penal médica ha sido en parte desarrollado por la jurisprudencia del Tribunal Supremo Español y la doctrina de dicho país, fundamentalmente por las implicancias penológicas que derivan de su diferenciación ${ }^{104}$ con la culpa leve. Ya antes de la dictación del Código Penal Español de 1995, Silva Sánchez explicaba que el límite inferior de la imprudencia - la tarea de fijar cuáles riesgos son irrelevantes y cuáles no - era un asunto "altamente complejo" ${ }^{105}$ A juicio de dicho autor, la fijación de tales fronteras de punibilidad implican determinar en qué nivel de peligrosidad de cierta conducta puede empezar a hablarse de una infracción al imperativo de cuidado, para lo cual debemos atender tanto a la magnitud del daño como a la probabilidad del mismo, cuyo producto nos arrojará una variable cuantitativa de referencia. Junto a ello, es necesaria una decisión valorativa al tenor de la cual podamos afirmar que en un contexto social dado, la relevancia penal de una determinada conducta comienza con una peligrosidad índice, la cual puede fluctuar según la presencia de factores culturales y espaciales ${ }^{106}$ contingentes. Lo anterior no es sino reflejo del criterio de riesgo permitido como elemento de la teoría de la imputación objetiva en el sistema moderno de atribución jurídico penal.

Los criterios jurisprudenciales para abordar los baremos de riesgos médicos penalmente relevantes han sido abordados por Hava, quien cita una sentencia de la Audiencia Provincial de Madrid de enero de 2000, como síntesis del estado actual de las directrices de los tribunales españoles sobre la materia:

“a) La no incriminación, vid. delito o falta, de la imprudencia en función de un error científico o del diagnóstico equivocado, ${ }^{107}$ cuando se haya cumplido en el reconocimiento de la "lex artis", salvo cuando por su propia categoría y entidad cualitativa resultan de extraordinaria gravedad, es decir, sólo la equivocación burda, inexplicable, absurda, podrá dar lugar a un delito que se produce en este ámbito y

\footnotetext{
${ }^{104}$ A las cuales hemos hecho referencia en cit. nota $\mathrm{n}^{\circ} 54$.

${ }^{105}$ SILVA, "Aspectos", cit. nota $\mathrm{n}^{\circ} 102, \mathrm{p} .45$.

${ }^{106}$ SILVA, "Aspectos", cit. nota n ${ }^{\circ} 102$, pp. 45-46. Silva ilustra lo anterior citando una sentencia del Tribunal Supremo Español, de fecha 22 de abril de 1988, que indica que es "asimismo notorio que en las aportaciones efectuadas a "vida o muerte", es decir en aquellas motivadas por dolencias agudas o por graves heridas y traumatismos, podrá ser disculpable no sólo la falta de éxito de una intervención que constituye remedio postrero y urgente, sino la no adopción de muchas de las cautelas que se toman en una operación que no urge".

${ }^{107}$ Coincide este criterio con el del artículo 24 del Código de Ética del Colegio Médico Chileno, que en lo pertinente señala "No son sinónimos de negligencia el diagnóstico erróneo (...)". Advierte sin embargo SILVA SÁNCHEZ que el médico sí responderá por los errores de diagnóstico o científicos vencibles, reconociendo sin embargo que dada las características propias de la medicina, el desconocimiento de muchas de las propiedades del cuerpo humano - que persiste hoy - trae como consecuencia muchas situaciones susceptibles de presentar errores invencibles. SILVA, "Aspectos", cit. nota n ${ }^{\circ} 102$, p. 47. Lo anterior sin duda ha sido recogido por la jurisprudencia de ambos países: En Chile, un fallo de la Corte Suprema de fecha 25 de abril de 1991, citado por PAILLÁS PEÑA, Enrique, La Responsabilidad Médica, Santiago: Editorial Jurídica Conosur, 1995, p. 96, estimó que el diagnóstico errado vencible (desestimando el de otro médico que deriva al paciente) causante de un hecho lesivo, es constitutivo de negligencia penal.
} 


\section{Polit. crim. Vol. 6, № 12 (Diciembre 2011), Art. 1, pp. 214 - 251. [http://www.politicacriminal.cl/Vol_06/n_12/Vol6N12A1.pdf]}

generalmente, no tanto por el actuar médico con o sin acierto, sino por el abandono, desidia o dejación de sus más elementales obligaciones.

b) Tampoco se reputa como elemento constitutivo, sin más, de la imprudencia, el hecho de carecer el facultativo de una pericia que pueda considerarse extraordinaria o de cualificada especialización, la imprudencia ha de medirse desde la perspectiva del médico normal. ${ }^{108}$

c) No es posible en este campo hacer una formulación de generalizaciones aplicables a todos los supuestos, sino que es indispensable, acaso con mayor razón que en otros sectores, la individualizada reflexión sobre el supuesto concreto que se trate.

d) Más allá de puntuales diferencias técnicas o científicas, salvo cuando se trate de supuestos muy calificados, ha de ponerse el acento de la imprudencia en el comportamiento específico del profesional, que pudiendo evitar con una diligencia exigible a un médico normal (la diligencia media por sus conocimientos y preparación), el resultado lesivo para una persona, no pone a contribución una actuación encaminada a contrarrestar las patologías existentes, con mayor o menor acierto, si este arco de posibilidades está abierto a la actuación ordinaria del profesional de la medicina; es decir, que ha de apreciarse en conjunto, la intervención del profesional en el diagnóstico, en la terapia, operación quirúrgica y sus reacciones en el curso de la enfermedad". ${ }^{109}$

Por su parte, Silva Sánchez señala que los elementos empleados por el Tribunal Supremo Español para determinar la gravedad de la imprudencia médica son: 1.- La mayor o menor intensidad de la falta de atención o cuidado; 2.- La mayor o menor representación del evento previsible y evitable; y 3.- La magnitud de la infracción del deber normativo. A juicio del autor, junto con ello, en el plano subjetivo debemos ponderar el grado de

\footnotetext{
${ }^{108}$ Este criterio apunta, en principio, a sostener la tesis mayoritaria sobre la valoración de las capacidades, conocimientos o habilidades especiales del sujeto, en cuanto las excluye del injusto típico, relegando su análisis a nivel de culpabilidad. ROXIN, Derecho Penal, cit. nota ${ }^{\circ} 45$, p. 1013, tesis denominada del doble baremo. También: CEREZO, Mir, "El tipo de lo injusto de los delitos de acción culposos", Anuario de Derecho Penal y Ciencias Penales, (1983), pp. 471 y ss. Así, el cirujano que no emplea sus aptitudes extraordinarias en una operación, limitándose a emplear el modelo de previsión exigible al galeno medio, incurriría en una conducta penalmente atípica. Esto se opone al criterio que se desprende del artículo 24 del Código de Ética del Colegio Médico de Chile, que señala: "Será negligente el médico que poseyendo los conocimientos o la destreza requerida, no la haya aplicado, teniendo a su alcance los medios para hacerlo", conforme al cual se podría sostener que en nuestro país, el conocimiento especial o extraordinario del galeno sí es valorable a nivel de tipicidad. En este sentido, entre nosotros, Alex Van Weezel, ha sostenido la denominada tesis individualizadora, afirmando que dichos conocimientos deben ponderarse ya en el tipo y que incluso la misma tesis generalizadora $\mathrm{u}$ objetiva incluye aspectos de tales factores al estudiar la previsibilidad objetiva de la conducta. VAN WEEZEL DE LA CRUZ, Alex, "Parámetros para el enjuiciamiento de la infracción al deber de cuidado den los delitos imprudentes", Revista Chilena de Derecho, Vol. 26, n², (1999), pp.323-336.

${ }^{109}$ HAVA, La Imprudencia, cit. nota $n^{\circ} 19$, p. 88. El fallo cita a su vez, sentencias del Tribunal Supremo Español de fechas 17 de julio de 1982, 24 de noviembre de 1984, 22 de diciembre de 1986, 27 de mayo de 1988, 13 de marzo de 1990, 4 de septiembre de 1991, 21 de abril de 1992, 8 de junio de 1981, 27 de mayo de 1988, 14 de febrero de 1991, y 13 de noviembre de 1992.
} 
MARTÍNEZ, Marco. "La graduación del deber de cuidado en el delito culposo por Actos de mala praxis médica: un análisis dogmático, jurisprudencial y económico".

conocimiento del sujeto sobre el riesgo y considerar en todo caso la utilidad social ${ }^{110}$ de la conducta en términos de su tolerabilidad colectiva. ${ }^{111}$

A nuestro juicio, el concepto de culpa grave se define sobre una valoración global de la imputación subjetiva del comportamiento ${ }^{112}$ y el estándar de riesgo permitido, como asimismo sobre la entidad de la infracción del respectivo imperativo de diligencia. ${ }^{113}$ En relación a lo primero, como ya ha explicitado Van Weezel, deben considerarse tres momentos sucesivos en la ejecución de la acción: la previsibilidad del riesgo, su valoración, y la actuación consecuente; mientras que en cuanto a las potencias del agente, corresponde considerar tanto los conocimientos como las especiales capacidades o habilidades del autor, ${ }^{114}$ debiendo atenernos a dichos elementos en la configuración del ilícito culposo, sea conforme a la tesis generalizadora corregida ${ }^{115} \mathrm{o}$ al tenor de su inserción en el tipo, según la tesis minoritaria individualizadora. ${ }^{16}$ En cuanto al deber de cuidado, su estudio dependerá de la relevancia de la obligación médica vulnerada, cuestión que ha de vincularse con los imperativos fundamentales de la profesión médica ${ }^{117}$ y el nivel de riesgo

${ }^{110}$ Lo que nos replantea la necesidad de valorar la eficiente asignación de recursos como elemento interpretativo sobre la fijación de los límites del riesgo penalmente relevante.

111 SILVA, "Aspectos", cit. nota $\mathrm{n}^{\circ} 102$, p. 46-47. Lo cual se vincula con los modernos criterios de imputación objetiva en razón de la tolerabilidad y adecuación social del acto médico.

${ }^{112} \mathrm{La}$ intensidad en la previsión individual del agente, así como la valoración de sus conocimientos y habilidades especiales constituye la razón fundamental del por qué de la distinción en sede penal, y en donde recae su mayor aplicación práctica a nivel jurisprudencial.

${ }^{113}$ HAVA, La imprudencia, cit. nota $\mathrm{n}^{\circ} 19$, p. 150 , señala que la diferencia entre culpa grave y leve se determina a partir de la entidad del bien jurídico infringido, a diferencia de la distinción entre imprudencia consciente e inconsciente que se fija en función de si el autor ha previsto o no la posibilidad del resultado concreto.

${ }^{114}$ VAN WEEZEL, "Parámetros", cit. nota n 108, p. 324.

115 Propuesta por ROXIN, Derecho Penal, cit. nota ${ }^{\circ}$ 45, p. 1015. Siguiendo esta línea, JESCHECK, ha expresado que "sólo cuando esta comprobada la vertiente objetiva del hecho imprudente (tipo de injusto) puede examinarse adicionalmente si también se ha cumplido el mandato general de cuidado y previsión dirigido al autor individual, de conformidad con su inteligencia, formación, habilidad, cualificación, experiencia vital y su posición social (tipo de culpabilidad)". JESCHECK, Hans-Heinrich, Tratado de Derecho Penal: Parte General, Trad. OLMEDO CARDENETE, Miguel, Granada: Editorial Comares S.L., 2002, p. 608. Se entiende corregida la tesis generalizadora, ya que ROXIN propone incluir la postura individualizadora en el baremo de cuidado exigible respecto de las capacidades superiores del agente, manteniendo sin embargo el análisis de dichas cualidades a nivel de culpabilidad cuando se refiere a las capacidades inferiores del autor. ROXIN, Derecho Penal, cit. nota n ${ }^{\circ} 45$, p. 1017.

${ }^{116}$ VAN WEEZEL, "Parámetros", cit. nota ${ }^{\circ} 108$, pp. 326-327, hace presente que la postura generalizadora ve en los casos del cirujano que no utiliza sus especiales capacidades un delito de omisión imprudente, ante lo cual el autor critica que para configurar la omisión se haga depender la realización típica de los poderes individuales del sujeto, mientras que en el delito de comisión imprudente se utilice la tesis objetiva del hombre medio. Sobre el particular, siguiendo un planteamiento ecléctico: ROXIN, Derecho Penal, cit. nota ${ }^{\circ}$ 45, p. 1015. Las ventajas de la tesis generalizadora han sido resaltadas por JESCHECK en tanto: 1.- a través de la valoración autónoma del injusto de acción se crea un contrapeso frente a la responsabilidad por el resultado que a menudo se acentúa en la praxis de manera muy intensa; y 2.- pues puede ser anudada al hecho imprudente la adopción de medidas de seguridad cuando el autor adolece de incapacidad de culpabilidad. JESCHECK, Tratado, cit. nota $\mathrm{n}^{\circ} 115$, p. 608.

${ }^{117}$ Los deberes fundamentales de la profesión médica, según CESANO, son: la obligación de diagnosticar y tratar; de informar; de actuar en casos de urgencia o deber genérico de asistencia; de guardar secreto; de 
tolerado por nuestra sociedad, ${ }^{118}$ en conjunto con los demás elementos del tipo culposo de lesiones u homicidio.

La entidad de la faz subjetiva, especialmente referida a la previsibilidad individual y las capacidades del agente, constituye la ratio legis fundamental presente en la génesis de la distinción en clave penal, pues según Carrara ésta tenía por objeto determinar la culpa conforme pautas subjetivas y concretas en oposición a un análisis general y abstracto. ${ }^{119}$ Un intento por conceptualizar dichos grados de intensidad fue plasmado en el proyecto de Código Penal de 1868 de Carlos Tejedor en Argentina, ${ }^{120}$ siguiendo los comentarios de Pacheco, modelo que fue adoptado como legislación positiva en varias provincias de dicho país. ${ }^{121}$ En lo pertinente, el citado proyecto indicaba que existía culpa grave, entre otros casos:

" ${ }^{\circ}$ Cuando el autor del daño se ha apercibido del peligro de su acción, y sin embargo no se abstiene de ella por irreflexión o ligereza; $2^{\circ}$ Cuando el hecho encierra en sí tal grado de peligro, que basta la menor atención de parte del delincuente para apercibirse que el hecho podía producir el resultado ilícito; $3^{\circ}$ Cuando por razón de sus conocimientos personales o de las circunstancias en que se encuentra, el delincuente fuese capaz de prever el peligro de su acción o prevenir desagradables consecuencias; $(\ldots) "$

Mientras que estimaba concurrente culpa leve en los siguientes supuestos, entre otros:

actualizar conocimientos; de confrontar opiniones; y de derivar al paciente en caso necesario. Sin embargo, donde comúnmente se aprecia una cantidad mayor de deberes que inciden en la vida y salud de los pacientes, es en aquellos que inciden en el diagnóstico y tratamiento del usuario. Su infracción nace principalmente por los errores y omisiones que ocurren en su ejercicio, esto es, aquellos defectos en la aplicación de métodos, técnicas o procedimientos en las fases de actuación del profesional de la salud. En este marco, la doctrina ha clasificado los posibles errores de diagnóstico de la siguiente forma: a) errores por insuficiencia de conocimientos; b) por negligencia en el diagnóstico; c) por complejidad de cuadro clínico; mientras que los principales errores por implementación de un tratamiento, pueden sintetizarse como: a) errores respecto de los medios o recursos; b) en relación al organismo del paciente; c) en relación al tiempo de tratamiento; d) falta de coordinación del equipo médico; e) falta de control de elementos y aparatos técnicos; f) olvido de cuerpos extraños en las cavidades del paciente durante la operación; y g) falta de control de sangre para transfusiones. CESANO, "Los delitos", cit. nota n' 53, p. 741.

${ }^{118}$ Caso citado por SILVA supra, cit. nota $\mathrm{n}^{\mathrm{o}} 106$, relacionado con el riesgo permitido y adecuación social de la conducta.

${ }^{119}$ TERRAGNI, El delito, cit. nota $\mathrm{n}^{\circ}$ 103, pp. 28-29. Al respecto CARRARA explicaba que "Conforme esta norma de previsibilidad se regula la división de la culpa en lata, leve y levísima. Es lata cuando el resultado dañoso se hubiera podido prever por todos los hombres. Es leve cuando se hubiera podido prever únicamente mediante el empleo de una diligencia extraordinaria y no común", reconociendo que para su determinación en concreto se requiere considerar las condiciones individuales del agente. CARRARA, Programa, cit. nota $\mathrm{n}^{\circ}$ 100, pp. 145-146.

${ }^{120}$ ZAFFARONI/ALAGIA/SLOKAR, Derecho Penal, cit. nota n 45, p. 249.

${ }^{121}$ Concretamente en La Rioja (1876); Buenos Aires (1877); Entre Ríos, San Juan, Corrientes, San Luis y Catamarca (1878); Mendoza (1879); Santa Fe y Salta (1880) y Tucumán (1881). Junto con ello, dicho modelo también fue implementado en Paraguay (1880). ZAFFARONI/ALAGIA/SLOKAR, Derecho Penal, cit. nota $\mathrm{n}^{\circ} 45, \mathrm{p} 249$. 
MARTÍNEZ, Marco. "La graduación del deber de cuidado en el delito culposo por Actos de mala praxis médica: un análisis dogmático, jurisprudencial y económico".

" $1{ }^{\circ}$ Cuando la acción cometida por imprudencia no tiene más que una relación lejana con el resultado ilegal, y no ha podido preverse, sino como un efecto posible, pero inverosímil y no acostumbrado; (...) $3^{\circ}$ Cuando el agente se haya visto obligado por circunstancias urgentes, y que no puedan imputársele, a tomar resoluciones súbitas $(\ldots)$. ${ }^{122}$

La doctrina continental moderna comparte estos criterios como elementos definidores de la distinción teórica y legal entre culpa grave y leve, en sede punitiva, ${ }^{123}$ los que hemos de complementar con postulados de imputación objetiva en razón de la relevancia y adecuación social del acto sanitario.

Las tipologías de casos de culpa leve o de ausencia de culpa en materia de mala praxis médica conocidos por la judicatura española con posterioridad a la reforma del Código Penal de ese país en 1995, pueden sintetizarse en los siguientes: ${ }^{124}$

1.- El error científico o de diagnóstico, cuando preceda a una actuación posterior conforme a la lex artis (o sea, que el tratamiento efectuado sea acorde a la enfermedad erróneamente diagnosticada). ${ }^{125}$

2.- La carencia de pericias extraordinarias o especialización cualificada por parte del galeno. ${ }^{126}$

${ }^{122}$ Citado por JIMÉNEZ DE AZUA, Tratado, cit. nota no 102 , p. 732.

${ }^{123}$ En este sentido MUÑOZ CONDE y GARCÍA ARÁN expresamente señalan que la diferencia entre culpa grave y leve se refiere a elementos de imputación subjetiva: "Sin embargo, dado que junto a la lesión del cuidado objetivamente requerido hay que tener en cuenta también la capacidad, rol específico y conocimientos especiales del sujeto que actúa, tanto para fundamentar la imprudencia, como para graduar su gravedad, debe distinguirse entre imprudencia grave y leve, según el grado de participación subjetiva del autor en el hecho y de la conciencia del peligro que supone la acción que realiza (...). Mientras mayor sea la lesión del cuidado subjetivo, más grave será la imprudencia”. MUÑOZ CONDE, Francisco; GARCÍA ARÁN, Mercedes, Derecho Penal: Parte General, Valencia: Editorial Tirant Lo Blanch, 2002, p. 290. Para CESANO, "Los delitos", cit. nota ${ }^{\circ} 53$, p. 769 , "el tipo imprudente se integra con una faz subjetiva, la que, a su vez, está conformada por la previsibilidad y la evitabilidad".

${ }^{124}$ HAVA, La imprudencia, cit. nota ${ }^{\circ} 19$, pp. 89-106.

${ }^{125}$ En auto de fecha 30 de marzo de 1999, la Audiencia Provincial de Burgos confirmó el sobreseimiento del médico que diagnosticó erradamente una flebitis superficial, resultando posteriormente que el paciente fallece, pero sin embargo el tribunal estimó que la conducta preventiva desplegada por el profesional de la salud fue más allá de la exigida conforme ese diagnóstico errado. El tribunal fundamentó su decisión señalando que: "El ilícito penal se comete cuando el facultativo actúa contra la "lex artis" con abandono, dejación, negligencia y el descuido de la atención que el paciente requiere, no siendo incriminable el simple error científico el diagnóstico equivocado, salvo que por su propia categoría y entidad cualitativa o cumulativa resulten de extrema gravedad". HAVA, La Imprudencia, cit. nota ${ }^{\circ} 19$, p. 89.

${ }^{126}$ Hava García cita una sentencia de la Audiencia Provincial de Toledo de fecha 29 de marzo de 2009, en la cual se condenó por imprudencia leve a un podólogo que al cortar la uña del primer dedo del pie derecho del paciente, le produjo una herida con hemorragia consecuente, la cual fue atendida en ese mismo instante por el acusado. Posteriormente, al persistir las molestias, el paciente regresa unos días después al hospital, diagnosticándosele "gangrena diabética", resultando en la amputación de su dedo. El tribunal funda su resolución en la escasa intensidad o relevancia de la impericia, señalando que "dicho corte no se ha demostrado que fuera extraordinariamente torpe, por lo que no estamos en presencia de la "mala praxis" en el sentido de equivocación inexcusable o sobresaliente incuria". HAVA, cit. nota $n^{\circ} 19$, p. 92. Nuevamente aquí 
Polit. crim. Vol. 6, № 12 (Diciembre 2011), Art. 1, pp. 214 - 251.

[http://www.politicacriminal.cl/Vol_06/n_12/Vol6N12A1.pdf]

3.- La actuación o intervención médica en contextos de urgencia. ${ }^{127}$

4.- La no derivación oportuna del paciente a especialista cualificado y la falta de contraste clínico del diagnóstico. ${ }^{128}$

5.- El retardo en la intervención o actuación del médico. ${ }^{129}$

Los primeros tres casos han sido entendidos por la jurisprudencia española como supuestos de ausencia de culpa, tanto por falta de la debida previsibilidad, valoración del riesgo y actuación conforme, como también por la ausencia de conocimientos y habilidades especiales no exigibles en virtud del estándar objetivo del "médico normal", ${ }^{130}$ mientras que los demás casos se refieren a la dicotomía culpa leve - culpa grave. El tercero destaca

debemos relacionar la decisión absolutoria con las capacidades y habilidades especiales del sujeto, y la previsibilidad del resultado. En este caso, no existió un conocimiento o una representación del sujeto en el sentido de que carecía de las aptitudes necesarias para la intervención (en cuyo caso podríamos estar ante culpa por asunción de riesgo en un contexto que podría serle exigible una conducta distinta), ni tampoco un alto grado de previsibilidad objetiva del resultado producido ya que desconocía que el paciente era diabético.

${ }^{127}$ Caso citado por SILVA SÁNCHEZ, cit. nota $\mathrm{n}^{\circ} 106$.

${ }^{128}$ En este contexto, la doctrina española cita dos sentencias relacionadas con este tipo de casos: sentencia de la Audiencia Provincial de Huelva de fecha 26 de enero de 2000, que condena por homicidio con imprudencia leve al cirujano que exploró superficialmente a un paciente, descartando una tromboflebitis, sin practicar las pruebas pertinentes con el sólo argumento que dada su experiencia de 25 años podía detectar una tromboflebitis fácilmente, y a pesar de ello el paciente fallece de tromboembolismo pulmonar masivo a los días siguientes. En dicho caso el tribunal señaló que "El confiar en la apreciación clínica, sin contraste con pruebas técnicas de fácil realización, en un caso que venía anunciado por un facultativo especialista de posible tromboflebitis - y ya sabemos su difícil apreciación clínica -constituyen imprevisión y ausencia de cautelas profesionales que por tener carácter leve deben calificarse como falta de simple imprudencia". Se estimó que la ausencia de diligencia en razón de la asunción de un riesgo sin tomar las providencias necesarias, poseía una exigencia mermada en tanto el diagnóstico era de no fácil apreciación y el galeno confiaba en sus aptitudes en virtud de su cualificación y conocimientos especiales. En relación a la falta de derivación oportuna, la Audiencia Provincial de Madrid, en fallo de fecha 28 de abril de 2000, condenó por negligencia leve al acusado que operó un juanete a su paciente, lo que finalmente le provocó secuelas de acortamiento del dedo del pie y rigidez en la articulación. Se estimo que existía imprudencia leve por no derivar a la paciente a un profesional médico con especialidad en cirugía ortopédica que hubiese valorado globalmente el cuadro infeccioso. HAVA, La imprudencia, cit. nota ${ }^{\circ}$ 19, p.98-99.

${ }^{129}$ Los casos de intervención tardía se citan en varias sentencias, y las pautas jurisprudenciales explican que el sólo retraso en la atención sanitaria no puede configurar el elemento relevante único a fin de entender concurrente negligencia grave cuando sobreviene un resultado típico, calificando estos supuestos como constitutivos de imprudencias leves. Así, en sentencia de fecha 24 de noviembre de 1997, el Tribunal Supremo Español señaló que existía negligencia leve en la conducta del anestesista que si bien aplicó de forma adecuada la anestesia, no reaccionó de forma oportuna para impedir la muerte del paciente por anoxia, omitiendo trasladar al paciente de manera inmediata al centro de cuidados intensivos. En igual sentido, otros fallos han estimado constitutivo de culpa leve supuestos de mero retardo en la intervención, tales como la sentencia de la Audiencia Provincial de Zaragoza de fecha 22 de mayo de 1999 y la sentencia del Tribunal Supremo de 8 de noviembre de 1999. HAVA, La imprudencia, cit. nota n ${ }^{\circ}$ 19, pp. 100-102.

${ }^{130}$ Ello a juicio de HAVA, La imprudencia, cit. nota $\mathrm{n}^{\circ}$ 19, p. 91, implica que los tribunales españoles han asumido la perspectiva objetiva o generalizadora del deber de cuidado a que hemos hecho referencia supra. Lo anterior sin perjuicio del análisis que la tesis generalizadora efectúa respecto de los límites inferiores a título de asunción de riesgos, y respecto de los límites superiores atendiendo al estándar propio de ese profesional conforme su especialidad. Al respecto ver JESCHECK, cit. nota $\mathrm{n}^{\circ} 115$, pp. 624-625. 
MARTÍNEZ, Marco. "La graduación del deber de cuidado en el delito culposo por Actos de mala praxis médica: un análisis dogmático, jurisprudencial y económico".

por combinar la adecuación social del acto junto con una atenuación de su reproche subjetivo.

En cuanto al error de diagnóstico, debemos destacar - tal como lo señala López Mesa invocando a la jurisprudencia Argentina - que en atención a las limitaciones de la medicina moderna, el médico que adopta un tratamiento errado con resultado típico sólo responderá por su negligencia incontestable y patente, y no cuando éste opta - entre varias alternativas científicamente admisibles - eligiendo "aquella que a su juicio y según las particularidades resulta más apta". ${ }^{131}$ Asimismo, como hemos reiterado, sólo el error científico o fallo técnico invencible podrá exculpar al galeno de su responsabilidad, no así aquél que era salvable ${ }^{132}$ tomando las medidas de previsión y cuidado mínimas requeridas para el caso. ${ }^{133}$

Por su parte, nuestra jurisprudencia ha transitado desde una etapa de cierta permisividad a un aumento sostenido de las condenas por actos de negligencia médica penal, ${ }^{134}$ como consecuencia de los factores sociológicos tras el fenómeno contemporáneo de la "medicina defensiva" a que hemos hecho referencia supra. ${ }^{135}$ Sin embargo los criterios comunes que ilustran los fallos hasta nuestros días permanecen, y desarrollaremos algunos de ellos pertinentes al presente trabajo - a continuación.

Como primera cuestión, se advierte una tendencia judicial a hacer eco de la idea persistente en la doctrina ${ }^{136}$ - en el sentido de atender a las particularidades propias de la

${ }^{131}$ LÓPEZ MESA, Marcelo J., "Teoría general de la responsabilidad civil médica en el Derecho Argentino y Comparado", En: LÓPEZ MESA, Marcelo, (Dir.), Tratado de responsabilidad médica. Responsabilidad civil, penal y hospitalaria, Bogotá: Editorial Ubijus, Legis Argentina S.A., 2007, pp. 192-193.

${ }^{132}$ SILVA, "Aspectos", cit. nota n ${ }^{\circ} 102$, p. 47.

${ }^{133}$ En este sentido: SZANTHÓ PONGRÁCZ, Gyorgy, "Definiciones respecto al error en la medicina", Revista médica de Chile, Vol. 129, n 12, (diciembre 2001), pp. 1466-1469.

134 GARRIDO MONTT, Mario, "Responsabilidad del médico y la jurisdicción", Revista Chilena de Derecho, Vol. 13, (1986), pp. 281-288, p. 284. Garrido argumenta la falta de rigor punitivo en tanto que a la fecha de publicación de su artículo - año 1986 - eran pocas las condenas en sede penal en contra los médicos, citando el autor mayormente casos de absoluciones (desde el caso del Dr. Sierra que fue absuelto en 1897 a pesar de diagnosticar un embarazo cuando se trataba de un tumor, hasta el de una sentencia de la Corte Suprema de 16 de mayo de 1985 que absolvió a un psiquiatra por la muerte de un joven en condiciones no bien determinadas, inocencia que fue acordada por falta del vínculo causal entre el supuesto acto negligente y el hecho de su fallecimiento), haciendo referencia sólo a una condena - entre otros pocos casos que señala recordar - confirmada por la Corte de Apelaciones de Santiago en 1983.

$135 \quad$ Cit. nota ${ }^{\circ} 22$ y 24.

136 Para el profesor Etcheberry la previsibilidad como elemento del delito culposo debe prestar especial atención a las circunstancias concretas en que se desenvuelve el acto médico. Así, por ejemplo, si en un determinado país, (como en Chile) los anestesistas fueran muy reducidos en relación a las prácticas quirúrgicas que demandare el sistema de salud, mientras que los protocolos y reglamentaciones de salud exigieran que sólo un médico especialista administrare dicha anestesia, entonces puesto que la norma debe contrastarse necesariamente con los postulados de lo humanamente posible, tales problemáticas requieren resolverse por el lado de la falta de reproche subjetivo por inexigibilidad de otra conducta del profesional médico. ETCHEBERRY, Alfredo, "Tipos penales aplicables a la actividad médica", Revista Chilena de Derecho, Vol. 13, (1986), pp. 271-280, p. 279. En igual sentido, para el Dr. Alberto Teke Schlicht, la función de saneamiento del galeno es de carácter dinámico, no estático, compleja, en que interactúan una serie de factores: el hecho o acto del médico y las circunstancias que lo rodean. Dentro de esto último, debemos 
Polit. crim. Vol. 6, № 12 (Diciembre 2011), Art. 1, pp. 214 - 251.

[http://www.politicacriminal.cl/Vol_06/n_12/Vol6N12A1.pdf]

actividad médica: la precariedad de medios, la presencia de imprevistos, el conocimiento limitado de las propiedades del cuerpo humano, todo lo cual necesariamente involucra la posibilidad de riesgos en ocasiones no disociables de la actividad de sanación como factor a ponderar al momento de evaluar la previsibilidad (tanto objetiva como individual) del resultado dañoso por parte del galeno. En este sentido resulta relevante lo expresado por la Corte Suprema Chilena, al considerar que:

" OCTAVO: (...) Es evidente que la actividad médica -operar, aplicar un electroshock, administrar drogas y remedios - puede provocar lesiones, heridas, maltrato físico y psíquico y también el fallecimiento de una persona, situaciones que entran en colisión con las normas tutelares penales que prohíben matar, mutilar, herir, golpear o maltratar a otro. Ante esta realidad, cabe preguntarse si el profesional médico puede llegar a cometer una de las figuras penales sancionadas como tales en el Código Penal. La respuesta a esta interrogante discurre en el sentido de excluir de su actuar el tipo doloso de lesiones corporales o de homicidio sobre el supuesto de una acción curativa, objetiva y subjetivamente realizada conforme a las reglas de las Lex Artis y con el debido cuidado. Lo ocurrente será esto último, es decir, que se prescindió del cuidado debido, caso en el cual, estaremos en presencia de un delito culposo o cuasidelito. Aquí volvemos a lo dicho al comienzo de este razonamiento, que los médicos se obligan a procurar la sanación del paciente poniendo toda su sabiduría, experiencia y empeño, pero no a un resultado en ese sentido. Estas ideas las recoge el artículo 24 del Código de Ética Profesional del Colegio Médico de Chile que señala "Ningún médico por la naturaleza de la ciencia y del arte que profesa, puede asegurar la precisión de su diagnóstico, ni garantizar la cura del paciente. El asunto se complica si pensamos que, en la actualidad, el médico no actúa solo, por el contrario, lo hace con la colaboración de otros médicos y auxiliares, conformando lo que se denomina en el decir hospitalario "equipo médico". Más aún, en innumerables ocasiones se encuentra constreñido en su actuar por la carencia o deficiencia de los instrumentos de apoyo que requiere para cumplir con la "Lex Artis". Por lo dicho, es indudable que se tiene que descartar la idea sustentada por algunos tratadistas de la absoluta irresponsabilidad de los profesionales médicos, por el contrario esta responsabilidad penal y civil existe, pero se hace necesario fijar "cuándo y “cómo establecerla."137

distinguir condiciones normales y anormales en que se puede desempeñar. Normales serían: condiciones ambientales idóneas, de tiempo suficiente para una adecuada atención del paciente, y disponibilidad de recursos. Por otro lado, hay un entorno anormal en: exceso de usuarios, presión por atender en cierto lapso de tiempo, insuficiencia de recursos técnicos y humanos, mala iluminación o ruidos, situaciones de urgencia, etc. Agréguese a ello, además, los riesgos inherentes a ciertos tratamientos, y la disposición personalísima, manifestada en una reacción impredecible, que puede presentar un paciente frente a una determinada terapia. TEKE SCHLICHT, Alberto, "El acto médico como fuente de responsabilidad penal", Revista Chilena de Derecho, Vol. 13, (1986), pp. 247-249. Sobre el particular también GARRIDO, "Responsabilidad”, cit. nota $\mathrm{n}^{\circ} 134, \mathrm{p} .285$.

${ }^{137}$ Causa rol 7.070 de 15 de septiembre de 2007. Pronunciado por la Segunda Sala de la Corte Suprema integrada por los Ministros Sres. Nibaldo Segura Peña, Hugo Dolmestch Urra, Carlos Kunsemuller Loebenfelder y los Abogados Integrantes Sres. Óscar Herrera Valdivia y Domingo Hernández Emparanza. 
MARTÍNEZ, Marco. "La graduación del deber de cuidado en el delito culposo por Actos de mala praxis médica: un análisis dogmático, jurisprudencial y económico".

En este contexto, como observa Garrido Montt, ${ }^{138}$ se evidencia un principio de contradicción entre un creciente incremento en las exigencias impuestas a los galenos frente a la precariedad de recursos aportados por nuestro país al sector público en salud, lo cual - a juicio del autor - hará inclinar al sentenciador por un veredicto de absolución ante la duda sobre la concurrencia de un supuesto de imprudencia sanitaria con resultado típico.

Ahora bien, dichos elementos han sido considerados por la jurisprudencia para sostener un criterio de culpa grave implícito en algunas de sus decisiones. En particular destacan algunos fallos que han hecho alguna referencia a la materia. En primer lugar, en sentencia de fecha 24 de abril de 2008, la Corte de Apelaciones de Rancagua absolvió al galeno que diagnosticó erradamente ${ }^{139}$ un dolor testicular, remitiendo al paciente a su hogar y recentando antiinflamatorios, en circunstancias que se trataba de una atrofia testicular, lo cual acarreó la extirpación del órgano, sosteniendo la judicatura que:

“(...) Como se sabe, no todo error médico constituye, per se, una negligencia culpable. Según Terragni, por lo general "en la actividad curativa aún el empleo correcto de la lex artis puede desembocar en un resultado infausto, ya que la Medicina no tiene todas las posibilidades de solución a los problemas de salud que pueden presentarse, ni siquiera en aquellos casos en que se sostenga que el profesional ha podido ejecutar algo más de lo ofrecido, si la falta de curación igual pudo ocurrir aún con una conducta suya más propicia. Suponiendo un error de diagnóstico, aparece de los antecedentes reseñados y de los que se acumulan en el fallo en examen, que tal yerro no habría sido grosero, porque la enfermedad diagnosticada guardaba relación incluso el informe del Servicio Médico Legal, aún desfavorable para el causado, lo consigna- con el cuadro presentado y comunicado por el paciente. El examen ecográfico posterior demostró que había una inflamación del epidídimo, de modo que en cuanto a la localización, signos y prognosis consecuente, la conducta del médico en cuestión no resulta atrabiliaria." 140

Tal como lo señala el fallo, al no estar en presencia de un error mayúsculo ni de un error esencial, por cuanto el médico acusado desplegó una atención bajo un estándar mínimo exigible en condiciones complejas -atención de urgencia, servicios especiales de atención cerrados, ausencia de un profesional especializado en el tema- no se configuran los presupuestos de la figura típica. ${ }^{141}$ Se observa aquí una ausencia de los elementos de gravedad aplicables tanto respecto de la faz objetiva como subjetiva de imputación del tipo culposo, sin una referencia expresa a la distinción en comento, pero de iguales implicancias

\footnotetext{
${ }^{138}$ GARRIDO, "Responsabilidad", cit. nota n 134, p. 286.

${ }^{139} \mathrm{Al}$ respecto, en España el diagnóstico errado como causal de configuración del tipo culposo en materia médica, por regla ha sido descartado cuando precede a una actuación posterior conforme a la lex artis. Así, el auto de 30 de marzo de 1999 de la Audiencia Provincial de Burgos confirmó el sobreseimiento, pues si bien el paciente había fallecido diagnosticándosele erradamente una flebitis superficial, la conducta preventiva adoptada por el médico acusado fue más allá de la exigida para semejante evaluación. Citado por HAVA, $L a$ imprudencia, cit. nota $\mathrm{n}^{\circ} 19$, p. 89. A lo anterior debemos tener presente los alcances que ya hemos referido, señalados por SILVA, “Aspectos", cit. nota n ${ }^{\circ} 102$, pp. 46-47.

${ }^{140}$ Considerando $8^{\circ}$, Sentencia rol n ${ }^{\circ} 188-2007$, redactada por el ministro Carlos Aránguiz Zúñiga.

${ }^{141}$ Considerando $7^{\circ}, 8^{\circ}$ y $10^{\circ}$ del fallo.
} 
prácticas. La menor exigencia que el ordenamiento efectúa al galeno que interviene en condiciones de precariedad deriva, por un lado, de una atenuación en el riesgo permitido por razones de utilidad social conforme al criterio expuesto por el Tribunal Supremo Español, ${ }^{142}$ así como también de un aplacamiento del reproche subjetivo en términos de una menor exigibilidad de otra conducta. ${ }^{143}$

Una referencia al tema del límite de lo punible a título culposo en relación al baremo de culpa grave, se encuentra en un fallo más reciente del Tercer Tribunal de Juicio Oral en lo Penal de Santiago, que condenó al psiquiatra quien en su calidad de garante no tomó las providencias necesarias para evitar el suicidio de su paciente diagnosticado con trastorno bipolar con peligro de auto eliminación, resolviendo que:

“ (...) En cuanto a lo subjetivo, de acuerdo con nuestro sistema jurídico la culpa puede ser grave, leve y levísima, sin embargo en nuestro Derecho penal se excluye, es decir, no se exige el cuidado extremo extraordinario, más allá de lo normal, por lo que establecido aquel presupuesto, la disquisión (sic) de los artículo 491 y 492 del Código Penal, hablan del máximo descuido, esto es, se refieren a culpa grave o lata, la denominada mera imprudencia, es decir, a la falta de cuidado que el hombre medio emplea en la actividad que desarrolla, es más que una falta de diligencia elemental, esto es, a las negligencias comunes cometidas por un profesional en el ejercicio de su arte $\mathrm{u}$ oficio, entonces, para los especialistas, la negligencia culpable equivale a descuido culpable, la omisión, entonces del deber de cuidado exigible a toda persona prudente y normal que desempeñe esa profesión. La que sin duda ha concurrido en la especie, en atención a como se ha venido razonando, se advierte la omisión por parte del acusado de los elementales deberes de cuidado exigibles a éstos. Existió entonces, un alto grado de previsibilidad, el médico tratante sabía de la existencia del riesgo suicida, fue él quien lo diagnosticó, la diligencia precisa de haber evitado el riesgo, era, ciertamente previsible para un profesional medio de la medicina, como se asentó, en virtud de las declaraciones de los profesionales que concurrieron, que suponía la práctica la disposición de un vigilante las 24 horas del día". ${ }^{144}$

Tal observación es relevante en tanto vincula la graduación de la culpa con niveles de intensidad en el análisis de la imputación subjetiva ${ }^{145}$-concretamente la previsibilidad

\footnotetext{
${ }^{142}$ SILVA, "Aspectos", cit. nota $\mathrm{n}^{\mathrm{0}} 102$, p. 46, analizando la menor exigencia de la norma social al médico que opera en situaciones de "vida o muerte", en la sentencia del Tribunal Supremo Español de fecha 22 de abril de 1988.

${ }^{143}$ Siguiendo a Etcheberry, quien señala que la previsibilidad debe valorar las condiciones y recursos materiales y humanos disponibles en el ejercicio de la medicina. Cit. nota $\mathrm{n}^{\mathrm{o}} 136$.

${ }^{144}$ Sentencia de fecha 12 de julio de 2009, considerando vigésimo tercero.

145 Sobre la vinculación de la distinción entre culpa grave y leve en esta materia con la previsibilidad individual, ver HAVA, La Imprudencia, cit. nota $n^{\circ} 19$, p. 150, nota a pie de página número 63, quien hace presente la tendencia en la jurisprudencia de dicho país a vincular la mayor o menor previsibilidad del agente con una mayor o menor exigencia del deber de cuidado omitido, citando sentencias del Tribunal Supremo Español de fechas 26 de mayo de 1987 y 5 de febrero de 1990, deslizando sin embargo críticas, en tanto si bien estima correcto valorar dicho elemento al ponderar la gravedad de la infracción, la efectiva previsión parece ser irrelevante, tomando en cuenta que incluso la imprudencia inconsciente puede en ocasiones ser más reprochable que la consciente. Al respecto: MUÑOZ/GARCÍA, Derecho Penal, cit. nota n 123 , p. 327.
} 
MARTÍNEZ, Marco. "La graduación del deber de cuidado en el delito culposo por Actos de mala praxis médica: un análisis dogmático, jurisprudencial y económico".

individual del resultado típico- a lo cual hemos hecho referencia supra, ${ }^{146}$ de paso acogiendo la tesis tradicional que excluye la culpa levísima como objeto de sanción penal. $^{147}$

En este mismo contexto, los tribunales chilenos han fallado siguiendo algunas de las pautas sentadas por la doctrina y jurisprudencia comparada citada. Así, en sentencia de la Excma. Corte Suprema de fecha 2 de junio de $1998,{ }^{148}$ se absolvió al médico general que atendió como anestesista al paciente que sufrió un paro cardíaco que le provocó la muerte, durante una intervención destinada a efectuarle una esterilización tubaria. Se estimó en dicho fallo que la ausencia de un anestesista especializado en el hospital clase $C$ en el cual ocurrió la contingencia, constituía un elemento relevante a fin de determinar la configuración del tipo culposo. A nuestro juicio, ello incide en una falta de capacidades especiales no exigibles en el contexto de urgencia, lo cual deviene en una cuestión de riesgo permitido. Asimismo, lo anterior implica una aplicación del baremo del "cirujano medio" en cuanto a los límites superiores de las capacidades individuales del sujeto, lo cual confirma de algún modo la tesis objetiva sobre este particular.

En relación al error en el diagnóstico o en el tratamiento, la Corte Suprema falló, en sentencia de fecha 19 de diciembre de 2006, absolviendo al médico que en su intervención le causó lesiones graves a un menor, a pesar de que uno de los informes periciales rendidos durante la etapa de prueba señalaba que existía un método menos agresivo disponible para tal procedimiento. Se estimó que el derecho del galeno a elegir fundadamente el tratamiento a aplicar (existían informes que señalaban que dicho tratamiento era contraindicado para menores) no configura culpa penalmente relevante en caso que la actuación previa y consiguiente fuese conforme a la lex artis médica, efectuada de manera oportuna y diligente. ${ }^{149}$ Lo anterior no hace sino confirmar los criterios diferenciación de baremos expuestos de manera lata en el presente trabajo. ${ }^{150}$

\footnotetext{
${ }^{146}$ Cit. nota ${ }^{\circ} 111$ y 117.

147 JIMÉNEZ, Tratado, cit. nota $\mathrm{n}^{\circ} 102$, p. 979, En igual sentido, ROXIN, cit. nota $\mathrm{n}^{\circ} 45$, p. 1028, quien además propone como alternativa eximir de pena a la actuación insignificantemente imprudente encuadrando los casos como causas de exculpación por inexigibilidad. En igual sentido: TERRAGNI, El delito, cit. nota ${ }^{\circ}$ 103, p. 30. En Alemania, el profesor Jescheck hace presente que el denominado Proyecto Alternativo de Código Penal de 1969 preceptuaba que la imprudencia leve era siempre impune por faltar en ella la culpabilidad criminal. JESCHECK, Tratado, cit. nota $n^{\circ} 115$, p. 613. También en Alemania, Stratenwerth, ha señalado que la idea de que la responsabilidad por imprudencia se extienda a todos los peligros que el obligado podría conjurar prestando óptima atención y cautela, parte del supuesto irreal de que toda falta es evitable. Porque aunque dejáramos de lado los estados físicos o psíquicos excepcionales, nadie puede mantener permanentemente semejante grado de atención, esfuerzo y velocidad de reacción. El hecho de que tal error sea evitable por principio, no significa que pueda ser evitado por excepción. Por ello, dicho autor concluye que es recomendable, teniendo en vista el fin de la pena, que ésta se limite sólo a las transgresiones graves contra las normas sociales. STRATENWERTH, Günther, Derecho Penal, Parte General I: El hecho punible, Trad. CANCIO MELIÁ, Manuel y SANCINETTI, Marcelo A., Buenos Aires: Editorial Hamburrabi Srl., 2005, p. 519.

${ }^{148}$ Revista de Derecho y Jurisprudencia, t. 95, $\mathrm{n}^{\circ}$ 2, sección $4^{\circ}$, (mayo-agosto 1998), p. 95.

${ }^{149}$ Considerandos sexto, y séptimo del fallo.

${ }^{150}$ Cit. nota $\mathrm{n}^{\mathrm{o}} 107,125$.
} 
La utilización implícita -y la referencia expresa en algunos casos- de los elementos diferenciadores de la culpa grave por parte de la judicatura nacional, demuestra un entendimiento de los aspectos, causas y consecuencias que un criterio de resolución opuesto implicaría en la aplicación de la normativa penal culposa en materia médica. La constatación de que ha existido un aumento explosivo de juicios y condenas por mala praxis responde sin embargo a un fenómeno de sociología jurídica que obedece a etiologías independientes, pero que no ha incidido en las soluciones que los tribunales deben brindarle a estos casos.

El análisis económico del impacto que la legislación penal ha significado para los actores del conflicto nos revela que la interpretación doctrinaria mayoritaria del artículo 491 del Código Penal no refleja un nivel óptimo de cuidado exigible a los profesionales de la salud, en términos de racionalidad, eficiencia, justicia y respeto por los valores que definen y subyacen a aquella rama del Derecho. Una solución al problema implica utilizar los criterios jurisprudenciales - tanto comparados como nacionales- para crear estándares, plasmando el concepto de culpa grave de contenido homogéneo y referenciable para un número indeterminado de casos. En otras palabras: permitiendo que la dogmática jurídica tome lo que la jurisprudencia ya intuyó, por aproximarse, tal vez, un poco más a la realidad.

\section{BIBILIOGRAFÍA}

BAKER, Tom, The Medical Malpractice Myth, University of Chicago Press, 2005.

BECKER, Gary, "Crime and Punishment", JPE, Vol. 4, (1968), pp. 169 - 217.

BIERSCHBACH, Richard A.; STEIN, Alex, "Overenforcement", The Georgetown Law Journal, Vol. 93:1743, (2005), pp. 1744-1745.

BRADLEY, Gerard V., “Overcoming Posner”, Michigan Law Review, Vol. 94, n 6, (mayo 1996), pp. 1-18.

BUSTOS RAMÍREZ, Juan, Derecho Penal, Parte General, Tomo I, Santiago: Ediciones Jurídicas de Santiago, 2007. , Juan, El delito culposo, Santiago: Editorial Jurídica de Chile, 1995.

CALABRESI, Guido, The Cost of Accidents, A Legal and Economic Analysis, Student Edition, New Haven and London: Yale University Press, 1970.

CAMPOS QUIROGA, Jaime A., "La responsabilidad de carácter culposo", Revista de Ciencias Penales, tomo XXXVII, (1981), pp. 107-129.

CARRARA, Franceso, Programa de Derecho Penal, Parte General, Vol. I., BogotáBuenos Aires: Temis-Depalma, 1977.

CESANO, José Daniel, "Los delitos de homicidio y lesiones imprudentes por mala praxis médica", En: LÓPEZ MESA, Marcelo, (Dir.), Tratado de Responsabilidad médica. Responsabilidad civil, penal y hospitalaria, Bogotá: Editorial Ubijus, Legis Argentina S.A., 2007. 
MARTÍNEZ, Marco. "La graduación del deber de cuidado en el delito culposo por Actos de mala praxis médica: un análisis dogmático, jurisprudencial y económico".

COASE, Ronald H., "The Problem of Social Costs", Journal of Law and Economics, Vol. 3, (octubre 1960), pp. 1-23.

CURY URZÚA, Enrique, "Contribución al estudio de la responsabilidad médica", Revista de Ciencias Penales, tomo XXXVII, (1981), pp. 97-105. , Derecho Penal: Parte General, Octava edición, Santiago: Ediciones Universidad Católica de Chile, 2005.

ETCHEBERRY ORTHUSTEGUI, Alfredo, Derecho Penal: Parte General, Tomo I, Tercera edición, Santiago: Editorial Jurídica de Chile, 1997.

, El Derecho Penal en la Jurisprudencia, Parte General, Tomo I, Santiago: Editorial Jurídica de Chile, 1987. Alfredo, "Tipos Penales Aplicables a la Actividad Médica", Revista Chilena de Derecho, Vol. 13, (1986), pp.271-280.

E. MACDOWELL, Sarah, "Doctors charged with manslaughter in the course of medical practice, 1795-2005: a literature review", Journal of the Royal Society of Medicine, Vol. 99, (2006), pp. $309-314$.

FLETCHER, George P., Basic Concepts of Criminal Law, New York: Oxford University Press, 1998.

GARRIDO MONTT, Mario, Derecho Penal: Parte General, Tomo II, Cuarta edición, Santiago: Editorial Jurídica de Chile, 2007.

, "Responsabilidad del médico y la jurisdicción", Revista Chilena de Derecho, Vol. 13, (1986), pp. 281-288.

GREMBI, Verónica, "Trends and duration of medical malpractice cases. Some evidence from the Italian Court of Cassation decisions (1970-2005)", JEL, (abril 2007), pp. 130. En: http://ssrn.com/abstract=983039 [visitado el 3-06-2011].

HAVA GARCÍA, Esther, La imprudencia médica, Valencia: Tirant Lo Blanch, 2001.

HORVITZ LENNON, María Inés; LÓPEZ MASLE, Julián, Derecho procesal penal chileno, Tomo I. Santiago: Editorial Jurídica de Chile, 2002.

JESCHECK, Hans-Heinrich, Tratado de Derecho Penal: Parte General, Trad. OLMEDO CARDENETE, Miguel, Granada: Editorial Comares S.L., 2002.

JIMÉNEZ DE AZÚA, Luis, Tratado de Derecho Penal, Tomo V, Sao Pablo: Editorial Losada, 1990.

LABATUT GLENA, Gustavo; ZENTENO VARGAS, Julio, Derecho Penal, Parte General, Tomo II, Séptima Edición, Santiago: Editorial Jurídica de Chile, 1990.

LUZÓN PEÑA, Diego Manuel, Curso de Penal: Parte General, Madrid: Editorial Universitas, 2002.

MATUS ACUÑA, Jean Pierre, "El Ministerio Público y la política criminal en una sociedad democrática", en: .AA.VV, Delito, pena, y proceso, Santiago: Editorial Jurídica de Chile, 2008. jurídica "Congreso", 1994.

MELLO, Michelle M.; STUDDERT, David M.; BRENNAN, Troyen A., "The New Medical Malpractice Crisis", New England Journal of Medicine, Vol. 348, (junio 2003), pp. 2281-2284. 
Polit. crim. Vol. 6, № 12 (Diciembre 2011), Art. 1, pp. 214 - 251.

[http://www.politicacriminal.cl/Vol_06/n_12/Vol6N12A1.pdf]

MONICO, Edward; KULKAMI, Rick; CALISE, Arthur; CALABRO Joseph; "The Criminal Prosecution of Medical Negligence", The Internet Journal of Law, Healthcare and Ethics, Vol. 5, n ${ }^{\mathrm{o}}$ 1, (2007), pp. 1-15.

MUÑOZ CONDE, Francisco; GARCÍA ARÁN, Mercedes, Derecho Penal: Parte General, Valencia: Editorial Tirant Lo Blanch, 2002.

NOVOA MONREAL, Eduardo, Curso de Derecho Penal: Parte General, Santiago: Editorial Jurídica de Chile, 2005.

OSSANDÓN WIDOW, María Magdalena, La formulación de los tipos penales. Valoración crítica de los instrumentos de técnica legislativa, Santiago: Editorial Jurídica de Chile, 2009.

PAILlÁS PEÑA, Enrique, La Responsabilidad Médica, Santiago: Editorial Jurídica Conosur, 1995.

PAREDES CASTAÑÓN, José Manuel, "El límite entre imprudencia y riesgo permitido en el Derecho penal. ¿Es posible determinarlo con criterios utilitarios?”, $A D P C P, \mathrm{t}$. XLIX, fasc. III, (septiembre-diciembre 1996), pp. 909-942.

PÉREZ OLEA, Jaime, "El tratamiento médico y la práctica médica", Revista de Ciencias Penales, tomo XXXVII, (1981), pp. 87-95.

POLITOFF LIFSCHITZ, Sergio; MATUS ACUÑA, Jean Pierre; RAMÍREZ GUZMÁN, María Cecilia, Lecciones de Derecho Penal Chileno: Parte General, Segunda edición, Santiago: Editorial Jurídica de Chile, 2003.

POLITOFF LIFSCHITZ, Sergio; ORTIZ QUIROGA, Luis, Texto y comentario del Código Penal Chileno, Tomo I, Santiago: Editorial Jurídica de Chile, 2002.

POSNER, Richard A., "A Theory of Negligence", The Journal of Legal Studies, Vol. 1, $\mathrm{n}^{\circ} 1$, (enero 1972), pp. 29-96. En: http://www.jstor.org/stable/72401, [visitado el 306-2011].

, Economic Analysis of the Law, Seventh edition, New York: Aspen Publishers, Wolters Kluwer Law \& Business, 2007.

QUICK, Oliver, "Prosecuting "gross" medical negligence: manslaughter, discretion, and the Crown Prosecution Service", Journal of Law and Society, Vol. 33, $\mathrm{n}^{\circ}$ 3, (septiembre 2006), pp. 421-450.

REVUELTA IGLESIAS, Ana Victoria, "El riesgo de la Judicialización de la medicina", Educ. méd., Vol. $\mathrm{n}^{\mathrm{o}}$ 9, $\mathrm{n}^{\mathrm{o}}$ 1, (2006), pp. 55-64. En: http://scielo.isciii.es/scielo.php?script=sci_arttext\&pid=S157518132006000600015\& lng=es\&nrm=iso, [visitado el 3-06-2011].

RITZ P., Juan; GARCÍA M., César; ORTEGA T., Dulia, "La reforma procesal penal chilena: nuevo marco médico-legal del ejercicio de la radiología", Revista Chilena de Radiología, Vol. 11, no 3, (2005), pp.142-149.

ROXIN, Claus, Derecho Penal: Parte General, Tomo I, Segunda edición, Trad. LUZÓN PEÑA, Diego- Manuel; DÍAZ; GARCÍA CONLLEDO, Miguel; DE VICENTE REMESAL, Javier, Madrid: Civitas, 1997.

SHARKEY, Catherine M., "Unintended consequences of medical malpractice caps", New York University Law Review, Vol. 80, n 2, (mayo 2005), pp. 391-512.

SHER, Noa, "New differences between negligence and strict liability and their implications in medical malpractice reform", University of Southern California Interdisciplinary 
MARTÍNEZ, Marco. "La graduación del deber de cuidado en el delito culposo por Actos de mala praxis médica: un análisis dogmático, jurisprudencial y económico".

Law Journal, Vol. 16, (2007), pp. 2-64. En: http://www.ssrn.com/abstract=964728, [visitado el 3-06-2011].

SILVA SÁNCHEZ, Jesús María, Aproximación al Derecho Penal Contemporáneo, Barcelona: J.M. Bosch, 2002.

, "Aspectos de la responsabilidad penal por imprudencia del médico anestesista, La perspectiva del Tribunal Supremo", $D S$, Vol. 2, (enero - diciembre 2004), pp. 45-47.

, La expansión del Derecho penal. Aspectos de la política criminal en las sociedades postindustriales, Segunda edición, Madrid: Civitas, 2001.

Boch, 1999.

, Medicinas alternativas e imprudencia médica, Ed.

SCLAR, David; HOUSMAN, Michael, "Medical malpractice and physician liability: examining alternatives to defensive medicine", Harvard Health Policy Review, Vol. 4, no 1, (2003), pp. 75-84.

STEIN, Alex, "Fixing Medical Torts by Repositioning Inalienability and Contract", Cardozo Legal Studies Research Paper, $\mathrm{n}^{\mathrm{o}}$ 151, 2006, pp. 1 y ss. En: http.//www.ssrn.com/abstract=889474 [visitado el 3-06-2011].

STRATENWERTH, Günther, Derecho Penal, Parte General I: El hecho punible, Trad. CANCIO MELIÁ, Manuel y SANCINETTI, Marcelo A., Buenos Aires: Editorial Hamburrabi Srl., 2005.

SVATIKOVA, Katarina, "Economic criteria for criminalization: Why do we need the Criminal Law?", Rotterdam Institute of Law and Economics (RILE), Working Paper Series, ${ }^{\circ}$ 2008/12, marzo 2009, p. 1-28, p. 5. En: http: //ssrn.com/abstract=1150689. [visitado el 3-06-2011].

SZANTHÓ PONGRÁCZ, Gyorgy, "Definiciones respecto al error en la medicina", Revista médica de Chile, Vol. 129, n 12, (diciembre 2001), pp. 1466-1469.

TEKE SCHLICHT, Alberto, "El acto médico como fuente de responsabilidad penal", Revista Chilena de Derecho, Vol. 13, (1986), pp. 247-249.

TERRAGNI, Marco Antonio, El delito culposo, Santa Fe: Rubinzal-Culzoni, 2003.

TREBILCOCK, Michael J.; DEWEES, Donald D.; DUFF, David G., "The medical malpractice explosion: an empirical assessment of trends, determinants and impacts", Melbourne University Law Review, Vol. 17, (diciembre 1990), pp. 539-565.

VAN WEEZEL DE LA CRUZ, Alex, "Parámetros para el enjuiciamiento de la infracción al deber de cuidado den los delitos imprudentes", Revista Chilena de Derecho, Vol. 26, n², (1999), pp.323-336.

ZAFFARONI, Eugenio Raúl; ALAGIA, Alejandro; SLOKAR, Alejandro, Derecho Penal: Parte General, Buenos Aires: Ediar Sociedad Anónima Editora, 2002. 